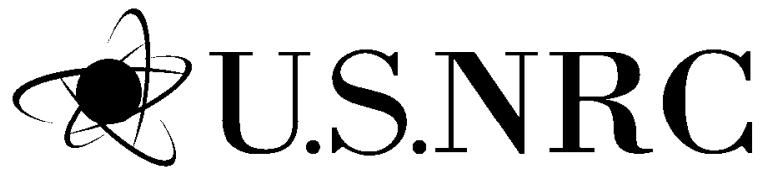

United States Nuclear Regulatory Commission

Protecting People and the Environment

\title{
Background and Derivation of ANS-5.4 Standard Fission Product Release Model
}




\section{AVAILABILITY OF REFERENCE MATERIALS IN NRC PUBLICATIONS}

\section{NRC Reference Material}

As of November 1999, you may electronically access NUREG-series publications and other NRC records at NRC's Public Electronic Reading Room at http://www.nrc.gov/reading-rm.html.

Publicly released records include, to name a few, NUREG-series publications; Federal Register notices; applicant, licensee, and vendor documents and correspondence; NRC correspondence and internal memoranda; bulletins and information notices; inspection and investigative reports; licensee event reports; and Commission papers and their attachments.

NRC publications in the NUREG series, NRC regulations, and Title 10, Energy, in the Code of Federal Regulations may also be purchased from one of these two sources.

1. The Superintendent of Documents

U.S. Government Printing Office

Mail Stop SSOP

Washington, DC 20402-0001

Internet: bookstore.gpo.gov

Telephone: 202-512-1800

Fax: 202-512-2250

2. The National Technical Information Service Springfield, VA 22161-0002

www.ntis.gov

1-800-553-6847 or, locally, 703-605-6000

A single copy of each NRC draft report for comment is available free, to the extent of supply, upon written request as follows:

Address: Office of Administration, Printing and Mail Services Branch U.S. Nuclear Regulatory Commission Washington, DC 20555-0001

E-mail: DISTRIBUTION@nrc.gov

Facsimile: 301-415-2289

Some publications in the NUREG series that are posted at NRC's Web site address http://www.nrc.gov/reading-rm/doc-collections/nuregs are updated periodically and may differ from the last printed version. Although references to material found on a Web site bear the date the material was accessed, the material available on the date cited may subsequently be removed from the site.

\section{Non-NRC Reference Material}

Documents available from public and special technical libraries include all open literature items, such as books, journal articles, and transactions, Federal Register notices, Federal and State legislation, and congressional reports. Such documents as theses, dissertations, foreign reports and translations, and non-NRC conference proceedings may be purchased from their sponsoring organization.

Copies of industry codes and standards used in a substantive manner in the NRC regulatory process are maintained at-

The NRC Technical Library

Two White Flint North

11545 Rockville Pike

Rockville, MD 20852-2738

These standards are available in the library for reference use by the public. Codes and standards are usually copyrighted and may be purchased from the originating organization or, if they are American National Standards, from-

American National Standards Institute 11 West $42^{\text {nd }}$ Street

New York, NY 10036-8002

www.ansi.org

212-642-4900

Legally binding regulatory requirements are stated only in laws; NRC regulations; licenses, including technical specifications; or orders, not in

NUREG-series publications. The views expressed in contractor-prepared publications in this series are not necessarily those of the NRC.

The NUREG series comprises (1) technical and administrative reports and books prepared by the staff (NUREG-XXXX) or agency contractors (NUREG/CR-XXXX), (2) proceedings of conferences (NUREG/CP-XXXX), (3) reports resulting from international agreements (NUREG/IA-XXXX), (4) brochures (NUREG/BR-XXXX), and (5) compilations of legal decisions and orders of the Commission and Atomic and Safety Licensing Boards and of Directors' decisions under Section 2.206 of NRC's regulations (NUREG-0750). 
United States Nuclear Regulatory Commission

$\overline{\text { Protecting People and the Environment }}$

\section{Background and Derivation of ANS-5.4 Standard Fission Product Release Model}

Manuscript Completed: March 2009

Date Published: January 2010

Prepared by

J.A. Turnbull ${ }^{a}$, C.E. Beyer ${ }^{b}$

${ }^{a}$ Consultant, United Kingdom

${ }^{\mathrm{b}}$ Pacific Norhwest National Laboratory 902 Battelle Boulevard

Richland, WA 99352

NRC Job Code N6326 



\begin{abstract}
This background report describes the technical basis for the newly proposed American Nuclear Society (ANS) 5.4 standard, Methods for Calculating the Fractional Release of Volatile Fission Products from Oxide Fuels. The proposed ANS 5.4 standard provides a methodology for determining the radioactive fission product releases from the fuel for use in assessing radiological consequences of postulated accidents that do not involve abrupt power transients. When coupled with isotopic yields, this method establishes the "gap activity," which is the inventory of volatile fission products that are released from the fuel rod if the cladding is breached.

Best-estimate and conservative upper-bound 95/95 tolerance models for predicting the release of volatile radioactive isotopes of krypton, xenon, and iodine are described. The isotope that provides the most significant contribution to equivalent dose to individuals is generally I-131 for accidents that occur during in-reactor operation or shortly after reactor operation (e.g., the fuel-handling accident) due to its dose to the thyroid. The existing conservative upper-bound model for predicting the I-131 release has been shown to be very conservative in comparison to the available measured release data for I-131. The 2009 model proposed herein predicts up to a factor of 2 lower release than the old ANS 5.4 release model.
\end{abstract}





\section{FOREWORD}

The U.S. Nuclear Regulatory Commission (NRC) has worked collaboratively with the American Nuclear Society (ANS) Working Group dealing with Methods for Calculating the Fractional Release of Volatile Fission Products from Oxide Fuels, otherwise known as ANS 5.4, to develop a standard for modeling fission product releases from oxide fuels. In 1982, the Working Group published NUREG/CR-2507, a precursor to the current report with the same title.

Over the intervening years, new data have become available from the Halden Reactor Project in Norway, which have shown that the assumptions used in the earlier standard may have been overly conservative. Collaborative efforts between the NRC and its contractor, Pacific Northwest National Laboratory, the nuclear industry, and the international community have lead to updated methods of determining the release of volatile fission products from the fuel. The technical basis for these revised methods is described in this report.

The ANS-5.4 standard provides a method for determining the fractional inventory of radioactive fission products released to the fuel-cladding gap during normal operation. This information, coupled with isotopic yields, establishes the "gap activity" or the fission product inventory that may be released if the cladding is breached during a postulated accident. Regulatory application of these results is further described in Alternative Radiological Source Terms for Evaluating Design Basis Accidents at Nuclear Power Reactors (Regulatory Guide 1.183).

The accident source term is intended to be representative of a major accident involving significant core damage and is typically postulated to occur in conjunction with a large loss-of-coolant accident (LOCA). Although the LOCA is typically the maximum credible accident, NRC staff experience in reviewing license applications has indicated the need to consider other accident sequences of lesser consequence but higher probability of occurrence. These design basis accidents (DBAs) were not intended to be actual event sequences, but rather, were intended to be surrogates that enable deterministic evaluation of the response of a facility's engineered safety features. These accident analyses are intentionally conservative in order to compensate for known uncertainties in accident progression, fission product inventory, transport, and atmospheric dispersion. As the state of knowledge has evolved, improvements in the methods used are now reflected in updates such as that described in this report. 



\section{CONTENTS}

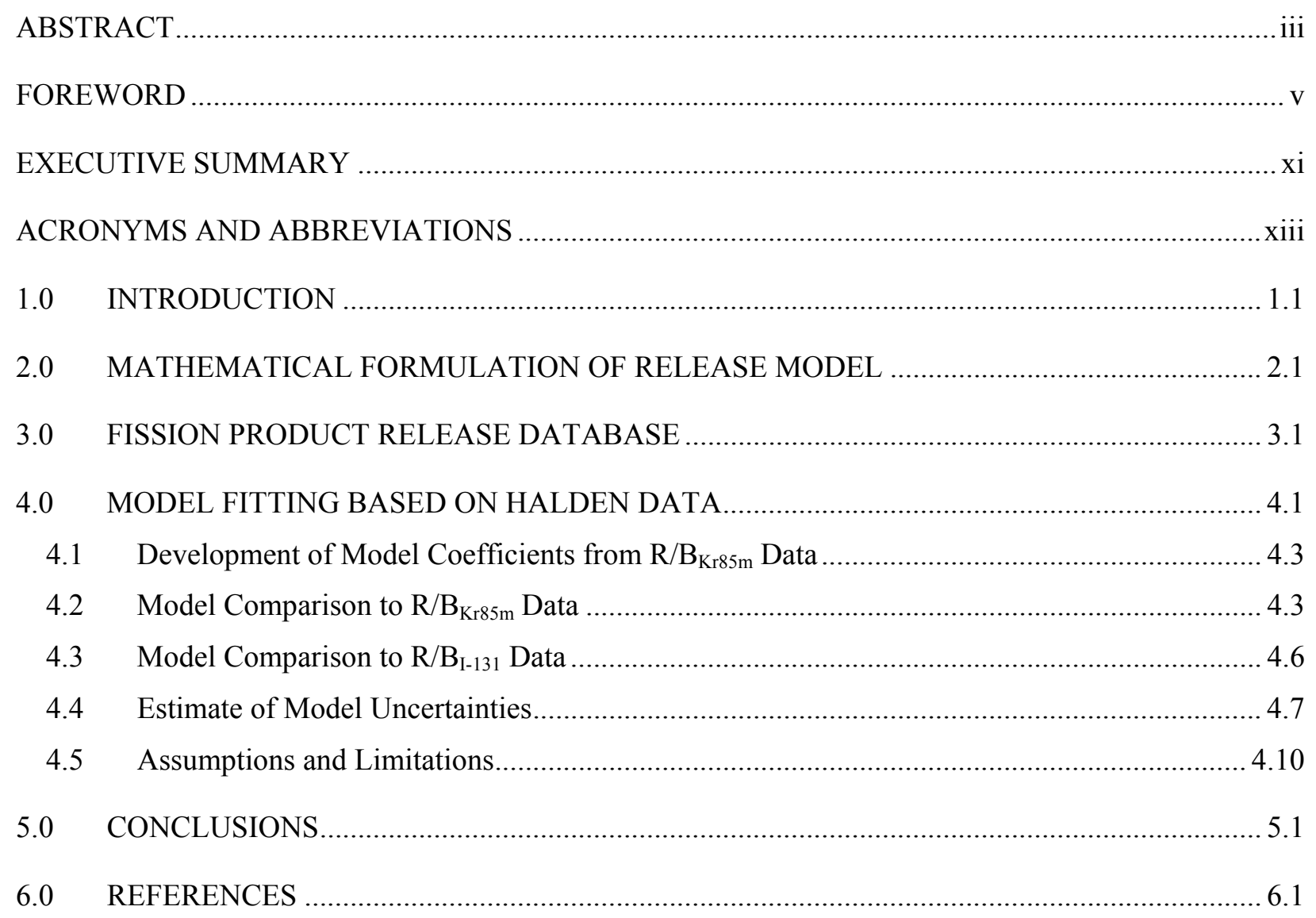





\section{FIGURES}

Figure 1 Operating Range of $\mathrm{Kr}-85 \mathrm{~m}$ and I-131 Release Data, $R / B$, from IFA-558, IFA-504, and IFA-633.

Figure 2 Ratio of Calculated $R / B_{\mathrm{Kr} 85 \mathrm{~m}}$ to Measured $R / B_{\mathrm{Kr} 85 \mathrm{~m}}$ Versus Burnup Between 0 and $90 \mathrm{MWd} / \mathrm{kgU}$ for Each of Six Experimental Rods in IFA-558 and Four Experimental Rods in IFA-504; Assumes $S / V_{1}=120 \mathrm{~cm}^{-1}$ and $S / V_{2}=650 \mathrm{~cm}^{-1}$

Figure 3 Ratio of Calculated $R / B_{\mathrm{Kr} 85 \mathrm{~m}}$ to Measured $R / B_{\mathrm{Kr} 85 \mathrm{~m}}$ Versus Burnup Between 0 and $40 \mathrm{MWd} / \mathrm{kgU}$ for Six Rods in IFA-558 (Red) and Four Rods in IFA-504 (Blue); Assumes $S / V_{1}=120 \mathrm{~cm}^{-1}$ and $S / V_{2}=650 \mathrm{~cm}^{-1}$

Figure 4 Ratio of Calculated $R / B_{\mathrm{Kr} 85 \mathrm{~m}}$ to Measured $R / B_{\mathrm{Kr} 85 \mathrm{~m}}$ versus Burnup for Six Rods in IFA558 (Red), Four Rods in IFA-504 (Blue), and Three Rods in IFA-633 (Green); Assumes $S / V_{1}=120 \mathrm{~cm}^{-1}$ and $S / V_{2}=650 \mathrm{~cm}^{-1}$

Figure 5 Ratio of Calculated $R / B_{\mathrm{Kr} 85 \mathrm{~m}}$ to Measured $R / B_{\mathrm{Kr} 85 \mathrm{~m}}$ Versus Rod Power for Six Rods in IFA-558 (Diamond), Four Rods in IFA-504 (Square), and Three Rods IFA-633 (Triangle); Assumes $S / V_{1}=120 \mathrm{~cm}^{-1}$ and $S / V_{2}=650 \mathrm{~cm}^{-1}$

Figure 6 Predicted to Measured $R / B$ for I-131 for IFA-558 and IFA-504; Assumes $S / V_{1}=120 \mathrm{~cm}^{-1}$ and $S / V_{2}=650 \mathrm{~cm}^{-1}$

Figure 7 Ratio of Calculated $R / B_{\mathrm{I}-131}$ to Measured $R / B_{\mathrm{I}-131}$ Versus Burnup Between 0 and $56 \mathrm{MWd} / \mathrm{kgU}$ for Three Rods in IFA-558 (Red) and Four Rods in IFA-504 (Blue); Assumes $S / V_{1}=120 \mathrm{~cm}^{-1}$ and $S / V_{2}=650 \mathrm{~cm}^{-1}$

Figure 8 Ratio of Predicted $R / B_{\mathrm{I}-131}$ to Measured $R / B_{\mathrm{I}-131}$ Versus Rod Power for Three Rods in IFA-558 (Red) and Four Rods in IFA-504 (Blue); Assumes $S / V_{1}=120 \mathrm{~cm}^{-1}$ and $S / V_{2}=650$ $\mathrm{cm}^{-1}$.

Figure 9 Predicted 95/95 (Assuming Non-Normal) $R / B_{\mathrm{Kr}-85 \mathrm{~m}}$ Versus Measured $R / B_{\mathrm{Kr}-85 \mathrm{~m}}$ from IFA504 and IFA-558

Figure 10 Predicted 95/95 (Assuming Non-Normal) $R / B_{\mathrm{I}-131}$ Versus Measured $R / B_{\mathrm{I}-131}$ from IFA504 and IFA-558

Figure 11 Comparison of New ANS 5.4 Model Upper Bound at 95/95 $R / B_{\mathrm{I}-131}$ Predictions to Old ANS 5.4 Model $R / B_{\mathrm{I}-131}$ Predictions for a BWR 10x10 Fuel Design

\section{TABLES}

Table 1 Half-Lives and Precursor Coefficients for Radioactive Nuclides..... 2.3

Table 2 Values of $S / V_{1}$ and $S / V_{2}$ that Provide a Best-Estimate Fit of $R / B_{\mathrm{Kr} 85 \mathrm{~m}}$ Data Versus Burnup from Experimental Test Assemblies IFA-558 and IFA-504 



\section{EXECUTIVE SUMMARY}

This background report describes the technical basis for the newly proposed American Nuclear Society (ANS) 5.4 standard, Methods for Calculating the Fractional Release of Volatile Fission Products from Oxide Fuels. The proposed ANS 5.4 standard provides a methodology for determining the radioactive fission product releases for use in assessing radiological consequences of postulated accidents that do not involve abrupt power transients. When used with isotopic yields, this method will establish the "gap activity," which is the inventory of volatile fission products that are available for release from the fuel rod if the cladding was breached. The standard as developed applies to steady-state conditions and, therefore, should not be applied to accidents where abrupt temperature increases are experienced, resulting in a "burst release." In addition, the standard does not consider escape-rate coefficients or other descriptions of the transport of fission products after release from the fuel rod void space. Finally, the standard assumes that no significant fuel oxidation will occur during the accident because fuel oxidation can significantly enhance the release.

The current standard applies to the release of the volatile and gaseous fission products of primary significance, which are krypton, xenon, iodine, cesium, and tellurium. This background document primarily addresses the diffusion coefficients and other model coefficients for krypton, xenon, and iodine and the data used to determine these coefficients. The diffusion coefficients for the precursors (bromine and tellurium) that impact the release of krypton and iodine are discussed briefly along with the data upon which they are based.

This report describes both best-estimate and conservative upper-bound 95/95 tolerance models for predicting the release of volatile radioactive isotopes of krypton, xenon, and iodine. The isotope that provides the largest contribution to equivalent dose to individuals is I-131 for accidents during in-reactor operation or shortly after reactor operation (e.g., the fuel-handling accident), due to its dose to the thyroid. The conservative upper-bound model for predicting the I-131 release has been shown to be very conservative in comparison to the available measured release data for I-131. The new proposed model predicts up to a factor of 2 lower release than the old ANS 5.4 release model. 



\section{ACRONYMS AND ABBREVIATIONS}

\begin{tabular}{ll}
$\alpha$ & precursor effect (unitless) \\
$\lambda$ & decay constant \\
$a$ & idealized sphere radius \\
$\mathrm{ANS}$ & American Nuclear Society \\
$B$ & production rate \\
$\mathrm{Br}$ & bromine \\
$B u$ & pellet average burnup \\
$\mathrm{BWR}$ & boiling water reactor \\
$C$ & nuclide concentration in fuel \\
$d$ & atomic jump distance \\
$D$ & diffusion coefficient \\
$\mathrm{DIDO}$ & nuclear research reactor, Harwell, Oxfordshire, U.K. \\
$F$ & fractal scaling factor \\
$\dot{F}$ & fission rate \\
$\mathrm{I}$ & iodine \\
$i$ & radial node \\
$j$ & axial node \\
$j$ & cation vacancy jump rate \\
$k$ & total number of radial nodes \\
$\mathrm{Kr}$ & krypton \\
$m$ & total number of axial nodes \\
$\mathrm{MOX}$ & mixed oxide \\
$\mathrm{MWd} / \mathrm{kgU}$ & megawatt-days per kilogram of uranium \\
$\mathrm{NRC}$ & U.S. Nuclear Regulatory Commission \\
$P$ & power \\
$p$ & time \\
$\mathrm{PNNL}$ & precursor nuclide \\
$r$ & racific Northwest National Laboratory \\
$R / B$ & radius of sphere \\
$\mathrm{S}$ & release-to-birth ratio \\
$S / V$ & seconds \\
$t$ & surface-to-volume ratio \\
\hline &
\end{tabular}





\subsection{INTRODUCTION}

The American Nuclear Society (ANS) standard, Method for Calculating the Fractional Release of Volatile Fusion Products from Oxide Fuel, ANS 5.4, ${ }^{1}$ provides a methodology for determining the radioactive fission product releases for use in assessing radiological consequences of postulated accidents that do not involve abrupt power transients. When used with isotopic yields, this method establishes the "gap activity," which is the inventory of volatile fission products that are released from the fuel rod if the cladding is breached. The standard as developed applies to steady-state conditions and, therefore, should not be applied to accidents where abrupt temperature increases are experienced, resulting in a "burst release." The standard does not consider escape-rate coefficients or other descriptions of the transport of fission products after release from the fuel rod void space. The standard assumes that no significant fuel oxidation will be present during the accident because fuel oxidation can significantly enhance the release.

The ANS 5.4 standard was first implemented in 1982 with Dr. Stan Turner as chairman of the Working Group ANS 5.4. The original methodology was based on the use of the Booth diffusion model ${ }^{1-4}$ and the coefficients to the model were determined from the measured release data of stable nuclides of xenon and krypton. The coefficients were derived using the stable nuclide release data because very little release data were available for the radioactive nuclides. The ANS 5.4 standard was implemented in the U.S. Nuclear Regulatory Commission (NRC) fuel performance code FRAPCON-2 by Pacific Northwest National Laboratory (PNNL). ${ }^{5}$ The 1982 standard was not reaffirmed in 1992 because newer data were demonstrating that the assumptions used in the earlier standard were overly conservative; however, many of the original Working Group members were not available to revise the standard at this time. A new Working Group ANS 5.4 was formed in 2000 to revise the standard. The following documents the ANS 5.4 standard proposed for implementation in 2009.

The proposed 2009 standard applies to the release of the volatile and gaseous fission products of primary significance, which are krypton, xenon, iodine, cesium, and tellurium. This background document primarily addresses the diffusion coefficients and other model coefficients for krypton, xenon, and iodine and the data used to determine these coefficients. The diffusion coefficients for the precursors (bromine and tellurium) that impact the release of krypton and iodine are discussed briefly along with the data upon which they are based.

The isotope that provides the largest contribution to equivalent dose to individuals is I-131 for accidents during in-reactor operation or shortly after reactor operation (e.g., the fuel-handling accident), due to its dose to the thyroid. These radioactive gaseous and volatile fission products can be divided into two categories: (1) short-lived radioactive nuclides (half-life less than one year) and (2) long-lived radioactive nuclides (half-life greater than one year). This division is significant because the most important release mechanism involves thermally activated migration (diffusion) processes that proceed slowly such that the short-lived nuclides decay appreciably before they are released from the pellet. Consequently, release calculations for short-lived nuclides must include their decay rate; whereas for long-lived nuclides, decay does not have to be considered.

The sections below will provide the background on the development of the mathematical formulations for the model, the fission product release data, model fitting to the release data including the uncertainties estimated from the model fitting, and the assumptions and limitations of the model. 



\subsection{MATHEMATICAL FORMULATION OF RELEASE MODEL}

The current ANS 5.4 Working Group has chosen to retain the simple phenomenological Booth diffusiontype model $^{1-4}$ proposed in the 1982 standard, and has fitted the model coefficients empirically to selected data whose characteristics will be described later. It should be stressed that the Booth diffusion model is a simplification of the physical processes involved in the release of fission products but has been shown to provide a reasonable fit to the release of both stable and radioactive nuclides. The actual physical process involves gas-atom diffusion to grain boundaries where the gas precipitates out on the boundary as a bubble. The gas bubbles are held on the grain boundary until the boundary is sufficiently saturated that interlinkage of the bubbles leads to a pathway out of the fuel and release to the inner void space of the fuel rod. In addition, gas bubbles are also precipitated within the grains; this gas is not released until sufficiently high temperatures are achieved. The gas within the grain matrix and grain boundary bubbles can also be redissolved back into the grain matrix and subsequently re-diffused to grain matrix or grain boundary bubbles. The simple Booth model used for the standard accounts for bubble interlinkage and release using a simple empirical correlation that is a function of burnup and fuel temperature that agrees with fission gas release data obtained at the Halden Reactor Project.

The "idealized" Booth model describes diffusion of fission-product atoms in a spherical grain of fuel material. The governing differential equation is:

$$
\frac{\partial C}{\partial t}=B-\lambda C-\frac{D}{r} \frac{\partial^{2}(r C)}{\partial r^{2}}
$$

where $C$ is the nuclide concentration (atoms- $\mathrm{cm}^{-3}$ ) in the fuel, $t$ is time in seconds (s), $B$ is the production rate (atoms- $\left.\mathrm{cm}^{-3}-\mathrm{s}^{-1}\right), \lambda$ is the decay constant $\left(\mathrm{s}^{-1}\right), r$ is radius of the sphere $(\mathrm{cm})$, and $D$ is the diffusion coefficient $\left(\mathrm{cm}^{2}-\mathrm{s}^{-1}\right)$. The latter term of this equation is the local mass flow of atoms at a radius $r$ (atoms- $\mathrm{cm}^{-3}-\mathrm{s}^{-1}$ ). Therefore, the rate of concentration change in a region of radius $r$ is equal to the rate of production minus the rate of decay minus the rate of loss by mass flow out of the region.

In the original ANS 5.4 standard, the release fraction is the ratio of the release to production rate. It is sometimes referred to as $R / B$ (where $B$ as defined above and $C=0$ is assumed at the sphere surface where $r=a)$ is given by:

$$
\begin{aligned}
& R / B=3\left[\frac{1}{\sqrt{\mu}} \operatorname{coth}(\sqrt{\mu})-\frac{1}{\mu}\right] \\
& \text { where } R=-3 \frac{D}{a}\left(\frac{\partial C}{\partial r}\right)_{r=a}\left(\text { atoms }-\mathrm{cm}^{-3} \mathrm{~s}^{-1}\right) \text {, and }
\end{aligned}
$$

$\mu=\frac{\lambda a^{2}}{D}$ (unitless)

Equation 2 is for equilibrium conditions (i.e., assumes a period of constant power operation over several half-lives of the nuclide for the $R / B$ in question [generally three half-lives is sufficient]). If the temperature and power operation changes within less than three half-lives, this equation provides a conservative prediction of $R / B$ if the maximum power and temperature is used during the time period in question and the power change is not large enough to elicit large burst releases. 
This diffusion equation assumes that a net flow of atoms occurs because of the existence of a concentration gradient within the sphere and that the flux of atoms is proportional to that gradient. The production rate $B$ and decay constant $\lambda$ in Equation 1 are known for the nuclides of interest, but the effective diffusion coefficients $D$ and idealized sphere radius $a$ in Equation 2 are unknown and must be determined from experimental data.

The release fraction for the current standard uses the same equation but defines the radius of the sphere, $a$, in terms of a surface area to volume ratio, $S / V$, which for a sphere is $a=3 /(S / V)$. Substituting $3 /(S / V)$ in place of coefficient $a$ in Equation 2, as proposed by Turnbull and Friskney, ${ }^{6}$ results in the following relationship:

$$
R / B=S / V \frac{1}{\sqrt{\frac{\lambda}{\alpha D}}}\left[\operatorname{coth} \sqrt{\mu}-\frac{1}{\sqrt{\mu}}\right]
$$

$\mu=\frac{9 \lambda}{(S / V)^{2} \alpha D}$

Note that $\alpha$ is a unitless term for precursor effects that were generally ignored in the 1982 standard with the exception of the nuclides Xe-133 and Xe-135. However, the current standard will include precursor effects for additional nuclides. This equation can be further simplified with only a small over prediction (by less than $5 \times 10^{-3}$ relative) for release values less than 0.02 with the following relationship:

$$
R / B=S / V \sqrt{\frac{\alpha D}{\lambda}}
$$

The $\alpha$ term is calculated based on a derivation by Friskney and Speight ${ }^{7}$ for precursor enhancement effects on diffusing species from the following relationship:

$$
\alpha=\left[\frac{1-(y / x)^{3}}{1-(y / x)^{2}}\right]^{2}
$$

where

$$
y=\sqrt{\frac{D_{p}}{\lambda_{p}}} \text { and } x=\sqrt{\frac{D_{\text {nuclide }}}{\lambda_{\text {nuclide }}}}
$$

where $D_{p}$ and $\lambda_{p}$ are the diffusion coefficient and decay constant of the precursor nuclide, $p$, while $D_{\text {nuclide }}$ and $\lambda_{\text {nuclide }}$ are the nuclide daughter product. Values of $\alpha$ based on the above equation are shown in Table 1 below. 
Table 1 Half-Lives and Precursor Coefficients for Radioactive Nuclides

\begin{tabular}{cccc}
\hline Nuclide & Half-life & Decay Constant, $\mathbf{s}^{-1}$ & $\boldsymbol{\alpha}$ \\
\hline $\mathrm{Xe}-133$ & $5.243 \mathrm{~d}$ & $1.53 \times 10^{-6}$ & 1.25 \\
$\mathrm{Xe}-135$ & $9.10 \mathrm{~h}$ & $2.12 \times 10^{-5}$ & 1.85 \\
$\mathrm{Xe}-135 \mathrm{~m}$ & $15.3 \mathrm{~min}$ & $7.55 \times 10^{-4}$ & 23.5 \\
$\mathrm{Xe}-137$ & $3.82 \mathrm{~min}$ & $3.02 \times 10^{-3}$ & 1.07 \\
$\mathrm{Xe}-138$ & $14.1 \mathrm{~min}$ & $8.19 \times 10^{-4}$ & 1.00 \\
$\mathrm{Xe}-139$ & $39.7 \mathrm{~s}$ & $1.75 \times 10^{-2}$ & 1.00 \\
$\mathrm{Kr}-85 \mathrm{~m}$ & $4.48 \mathrm{~h}$ & $4.30 \times 10^{-5}$ & 1.31 \\
$\mathrm{Kr}-87$ & $1.27 \mathrm{~h}$ & $1.52 \times 10^{-4}$ & 1.25 \\
$\mathrm{Kr}-88$ & $2.84 \mathrm{~h}$ & $6.78 \times 10^{-5}$ & 1.03 \\
$\mathrm{Kr}-89$ & $3.15 \mathrm{~min}$ & $3.35 \times 10^{-3}$ & 1.21 \\
$\mathrm{Kr}-90$ & $32.3 \mathrm{~s}$ & $2.15 \times 10^{-2}$ & 1.11 \\
$\mathrm{I}-131$ & $8.04 \mathrm{~d}$ & $9.98 \times 10^{-7}$ & 1.0 \\
$\mathrm{I}-132$ & $2.28 \mathrm{~h}$ & $8.44 \times 10^{-5}$ & 137 \\
$\mathrm{I}-133$ & $20.8 \mathrm{~h}$ & $9.26 \times 10^{-6}$ & 1.21 \\
$\mathrm{I}-134$ & $52.6 \mathrm{~min}$ & $2.20 \times 10^{-4}$ & 4.4 \\
\hline
\end{tabular}

The basic coefficients to the diffusion model were based on experiments performed during the 1970s in the DIDO research reactor at UKAEA Harwell, United Kingdom, published by Turnbulli, ${ }^{6,8}$ however, small deviations from the original coefficients were made to provide a better fit to the fission gas release data obtained at the Halden Reactor Project. These small deviations are within the scatter of Turnbull's DIDO release data.

The basic assumptions for the diffusion model developed in this report are:

1. Gas-atom diffusion from where the atoms are born in the fuel matrix is the mechanism for diffusion to the grain boundaries where the gas precipitates as bubbles.

2. The gas bubbles on the grain boundaries reach a saturation point where the bubbles interlink, releasing the gas to the fuel rod void volume.

3. The criterion for grain boundary interlinkage is a function of only temperature and burnup.

4. Once the grain boundary interlinkage has occurred, the grain boundary remains linked to the rod internal void volume for the rest of the irradiation (i.e., no resintering of the grain boundary is experienced).

5. Derivation of precursor enhancement factor $\alpha$ is valid if one of two conditions is met:

a. The precursor is immobile after release. This is believed to be the case with the xenon precursor, iodine, which plates out on the cooler parts of the cladding or sweep gas flow lines until it decays to xenon, where it is then swept out to the out-of-reactor detectors.

b. The precursor is mobile but has a half-life much less than the transit time from the fuel to the detector. This allows the precursor to decay to the daughter product before reaching the detector, which is the case for the krypton precursor, bromine.

Further assumptions in the derivation of the coefficients to this model are:

6. The nuclides are in radioactive equilibrium in terms of release and decay; this assumption is approximately correct if fuel temperatures remain constant for at least three half-lives of the nuclide. 
7. The diffusion coefficients for the nuclides of interest are assumed to be the same as xenon or a multiple of that for xenon, i.e., $D(\mathrm{Xe})=D(\mathrm{Kr})=D(\mathrm{I})=D(\mathrm{Br}) / 20=D(\mathrm{Te}) / 4$. The diffusion coefficients for iodine and noble gases are known to be similar based on the Halden, DIDO, and other measured release data. ${ }^{9,11,12}$ However, the diffusion coefficients for the precursors bromine (for krypton) and tellurium (for iodine) are of greater uncertainty. Killeen et al. ${ }^{13}$ estimated the bromine diffusion coefficient to be a factor of 20 higher than for the noble gases because the factor of 20 provided the best agreement in terms of release of the different krypton and xenon isotopes with similar decay constants (half-lives) for the IFA-504 release data. This factor of 20 diffusion for bromine was also used by White and Turnbul1 ${ }^{11}$ to obtain good predictions of the IFA-558 release data. Lewis et al. ${ }^{14}$ estimated the tellurium diffusion coefficient to be a factor of 4 greater than the noble gases based on trace irradiations ${ }^{15}$ and release from a failed fuel experiment in a hydrogen/steam atmosphere. ${ }^{16}$

The diffusion coefficient form was one proposed by Turnbull et al. ${ }^{10}$ as the sum of three components:

$D=D_{1}(T)+D_{2}(T, \dot{F})+D_{3}(\dot{F})$

$D_{l}$ is an intrinsic component applicable at high temperature and dependent only on temperature; it was assumed that the best values for $D_{l}$ were those found by Davies and Long ${ }^{17}$ and also fit the DIDO data well:

$D_{l}=7.6 \times 10^{-10} \exp \left(-7 \times 10^{4} / R T\right), \mathrm{m}^{2} / \mathrm{s}$

where $T$ is fuel temperature in degrees $\mathrm{K}$.

The coefficient $D_{2}$ was evaluated in terms of diffusion assisted by an irradiation enhanced uranium vacancy concentration; in this case, the diffusion coefficient depended on both temperature $T$ and the fission rate $\dot{F}$ :

$D_{2}=d^{2} \cdot j_{v} \cdot V c$, and $j_{v}, \mathrm{~m}^{2} / \mathrm{s}$

where $d$ is the atomic jump distance, $j_{v}$ is the cation vacancy jump rate, and $V c$ is the cation vacancy concentration, which is a function of fission rate and temperature. The exact relationship for $D_{2}$ was not provided in Reference 10 but was later provided by White and Turnbull. ${ }^{11}$

$D_{3}$ is an athermal, low-temperature diffusivity (diffusion is solely by irradiation damage) analogous to that derived by Matzke ${ }^{18}$ for irradiation-enhanced self-diffusion:

$D_{3}=2 \times 10^{-40} \dot{F}, \mathrm{~m}^{2} / \mathrm{s}$

where $\dot{F}$ is fission rate in fissions $/ \mathrm{m}^{3}$-s.

The pre-exponentials of the first two coefficients $\left(D_{1}\right.$ and $\left.D_{2}\right)$ have since been decreased by a factor of 10 and 1.8, respectively, (see first and second terms in Equation 9 below) to provide a better fit to the Turnbull et $\mathrm{al}^{6,10}$ and the Halden Reactor Project radioactive gas release data ${ }^{11}$ as determined by Turnbull. ${ }^{8}$ These data were measured by sweeping helium gas through a fuel rod that carries the radioactive gas within sealed flow lines to a location outside of the reactor core where it is counted with a detector to determine the amount of release within a given time period. These data are then converted to $R / B$. The decay that occurs between when the gas is released from the fuel to when it is counted, as well 
as detector counting efficiency, is used in determining $R / B$. These data are discussed further in Section 3.0 .

The revised three-term diffusion coefficients are expressed as:

$D_{i}=7.6 \times 10^{-11} \exp \left(-35000 / T_{i}\right)+1.41 \times 10^{-25} \dot{F}^{0.5} \exp \left(-13800 / T_{i}\right)+2 \times 10^{-40} \dot{F}, \mathrm{~m}^{2} / \mathrm{s}$

Bubble saturation and interlinkage at the grain boundaries have been modeled by several investigators with References 19 and 20 providing examples; however, many of these models estimate that saturation is dependent on external pressure on the fuel pellet. The assumption that saturation and release is dependent on external pressure was tested in the Halden experiment IFA-558, which demonstrated that gas pressure on the fuel pellet had very little or no impact on saturation and release. ${ }^{11}$ Therefore, a simple empirical correlation was used based on the Vitanza threshold criterion ${ }^{21}$ for release with a modification for higher burnup because the Vitanza threshold has been shown to underestimate the threshold for release at high burnup. The original Vitanza threshold fuel temperature dependence was based on fuel centerline temperature while that proposed in this model is based on local fuel temperature at a given radial node. This modification is conservative for determining release; however, it has been shown to provide a reasonable best estimate fit to the Halden release data of radioactive isotopes. The nodal temperature for the threshold, or in this case grain boundary bubble interlinkage, at low burnups is essentially that proposed by Vitanza as:

$$
T_{\text {link }}=\frac{9800}{\ln (176 \cdot B u)}+273
$$

if $B u \leq 18.2$ megawatt-days per kilogram of uranium ( $\mathrm{MWd} / \mathrm{kgU})$, where $B u$ is pellet average burnup.

For $B u>18.2 \mathrm{MWd} / \mathrm{kgU}$, the following relationship is used for interlinkage temperature:

$$
T_{\text {link }}=1434-12.85 B u+273
$$

where $T_{\text {link }}$ is in degrees K.

The release fraction for a given nuclide for an irradiation period at constant temperature and power of radial node $i$ has been modeled for a given radial node in a fuel pellet using Equation 4:

$$
\begin{aligned}
& \left(\frac{R}{B}\right)_{i, \text { nuclide }}=\left(\frac{S}{V}\right)_{i} \sqrt{\frac{\alpha_{\text {nuclide }} D_{i}}{\lambda_{\text {nuclide }}}} \\
& \left(\frac{S}{V}\right)_{1}=120 \mathrm{~cm}^{-1} \quad \text { if } T_{i} \leq T_{\text {link }} \\
& \left(\frac{S}{V}\right)_{2}=650 \mathrm{~cm}^{-1} \quad \text { if } T_{i}>T_{\text {link }}
\end{aligned}
$$

Where $T_{i}=$ fuel temperature for node $i$, in degrees $\mathrm{K}$. When interlinkage occurs at a given radial nodal temperature (i.e., $T_{i}>T_{\text {link }}$ ), the $S / V$ increases from $120 \mathrm{~cm}^{-1}$ to $650 \mathrm{~cm}^{-1}$. 
Release of I-131 has been modeled differently from the shorter half-life isotopes represented by the above equations. Release of long-lived isotopes such as I-131 (8.04-day half-life) is based on a fractal approach to the effective diffusion distance, or $S / V$ between long-lived versus short-lived isotopes, proposed by White. ${ }^{22}$ The fractal approach to diffusion to a given surface can be summarized by an analogy of measuring a coastline with rulers of different length: the longer the ruler, the shorter the coastline. The equivalent ruler for fission gas release is the distance that an isotope has to diffuse before decay. In this case, the effective surface area for short-lived species was larger (shorter diffusion distance) than that of long-lived species. Applying this fractal concept and equations proposed by White for diffusion leads to the following relationship for release of long-lived isotopes (half-lives greater than 4.48 hours) compared to the release of $\mathrm{Kr}-85 \mathrm{~m}$ (4.48-hour half-life):

$$
\left(\frac{R}{B}\right)_{i, \text {,uclide }}=F_{\text {nuclide }}\left(\frac{S}{V}\right)_{i} \sqrt{\frac{\alpha_{K r-85 m} D_{i}}{\lambda_{K r-85 m}}}
$$

$F_{\text {nuclide }}$ is a fractal-scaling factor for longer-lived nuclides defined as:

$$
F_{\text {nuclide }}=\left(\frac{\alpha_{\text {nuclide }} \lambda_{K r-85 m}}{\lambda_{\text {nuclide }} \alpha_{K r-85 m}}\right)^{0.25}
$$

$(S / V)_{i}, D_{i}$, and $\alpha_{\text {nuclide }}$ are as defined above. For I-131, Equation 13 becomes:

$$
\left(\frac{R}{B}\right)_{131}=2.39 \times\left(\frac{R}{B}\right)_{85 m}
$$

Modeling the release in a fuel rod with $k$ radial nodes and $j$ axial nodes can be determined by summing the release for a given nuclide with decay constant, $\lambda_{\text {nuclide }}$, from each radial and axial node at constant temperature and burnup, which is given by the following equation:

$$
\left(\frac{R}{B}\right)_{\text {nuclide }}=\sum_{j=1}^{m}\left[\frac{P_{j}^{\text {pellet }}}{P^{\text {ave }}} \frac{V^{\text {node }}}{V^{\text {rod }}} \sum_{i=1}^{k}\left(\frac{P_{i, j}^{\text {ring }}}{P_{j}^{\text {pellet }}} \frac{V_{i, j}^{\text {ring }}}{V^{\text {node }}}\left(\frac{R}{B}\right)_{i, j}\right)\right]
$$

where:

$P=$ power in $\mathrm{kW} / \mathrm{ft}$ (ave=rod average, pellet=pellet [axial node] average, ring=local radial ring)

$V=$ volume, $\mathrm{cm}^{3}$ (rod=total rod volume, node=axial node volume, ring=radial ring volume)

Equation 14 sums the radial and axial nodes to obtain release for a given nuclide in a fuel rod. 


\subsection{FISSION PRODUCT RELEASE DATABASE}

The radiological release database consists of $R / B$ data from Kr-90, Xe-139, Kr-89, Xe-137, Xe-138, Xe-135m, Kr-87, Kr-88, Kr-85m, Xe-135, Xe-133, and I-131; half-lives are presented in Table 1. The experimental measurements of $R / B$ of radioactive fission gases were obtained from three gas-flow type experiments (i.e., the Halden IFA-504, IFA-558, and IFA-633). The IFA-504 and IFA-558 Kr-85m data ${ }^{11}$ were used for model fitting and the limited amount of IFA-633 Kr-85m data ${ }^{23}$ and iodine data from IFA-504 and IFA-558 were used to verify the model. The IFA-504 experiment consisted of four rods irradiated to 60 to 90 gigawatt-days per kilogram of uranium $(\mathrm{MWd} / \mathrm{kgU})$ while IFA-558 consisted of six rods irradiated to $40 \mathrm{MWd} / \mathrm{kgU}$. These experiments flow gas over the fuel within the Zircaloy cladding for each rod, thus sweeping out the radioactive gas that is then collected outside of the reactor core and counted by a gamma detector to determine the quantity of gas released within a specific time period. In order to be able to measure the $R / B$ for modeling purposes, equilibrium must be established between the three rate-dependent processes of: 1) release of gas from the fuel; 2) rate of radioactive decay; and 3) gas production rate. For equilibrium to be established, the production rate and the fuel temperature (impacts diffusion rate) can not change significantly within three times the half-life of the radioactive gas release being measured. The model assumes that the gas species are released solely by diffusion, except for a small recoil component that is significant only for very short-lived species that do not impact dose consequences. This component will be ignored in the model presented here.

The iodine isotopes are solid except at high temperatures and are not transported through the unheated flow lines of a gas flow experiment to the gamma detector; this is important in the measurement of iodine release. Assessment of the iodine release presents some difficulties and must be performed indirectly by measurement of the xenon decay products. The situation is further complicated by the fact that the decay products (Xe-135, Xe-135m, Xe-133, and Xe-131m) are themselves released in sufficient quantities as to render at-power iodine measurement difficult. This situation is circumvented by exploiting the fact that production and release of the isotopes effectively ceases at reactor shutdown. Any excess xenon detected after shutdown must have arisen from decay of iodine isotopes already released and plated out on cooler parts of the gas circuit. Therefore to measure iodine release, at shutdown the rods are flushed thoroughly to remove any xenon actually released as xenon. This is followed by a number of on-line flow measurements taken at intervals over the following 24 hours. In this way, the release of I-135 and I-133 can be inferred from the Xe-135, Xe-135m, and Xe-133 activity.

The determination of I-131 release is more complicated because $99 \%$ of its decay results in the stable Xe-131 isotope, while the remaining $1.086 \%$ yields xenon that has a half-life of 11.9 days and whose gamma energy is in close proximity to a strong gamma ray from the decay of Xe-133 (5.29-day half-life). The technique adopted exploits the different half-lives of the isotopes in the decay chain. If the rod is sealed, the concentration of Xe- $131 \mathrm{~m}$ after 12 to 14 days reaches a maximum and, when swept out to the gamma detector, can be distinguished from any residual amounts of Xe-133 and used to estimate the quantity of I-131 released immediately prior to shutdown. The requirement for a long shutdown for this measurement means that only a few estimates of I-131 release have been possible. In all, a total of 21 measurements of I-131 release were made from the Halden gas flow experiments IFA-504 and IFA-558 using this measurement method.

The database for the gaseous and iodine species ranges from $14.4 \mathrm{~kW} / \mathrm{ft}$ up to $24 \mathrm{MWd} / \mathrm{kgU}$ burnup, $9 \mathrm{~kW} / \mathrm{ft}$ up to $60 \mathrm{MWd} / \mathrm{kgU}$, and $4 \mathrm{~kW} / \mathrm{ft}$ up to $90 \mathrm{MWd} / \mathrm{kgU}$ as demonstrated in Figure 1 . A linear interpolation between these ranges is reasonable for model application. 


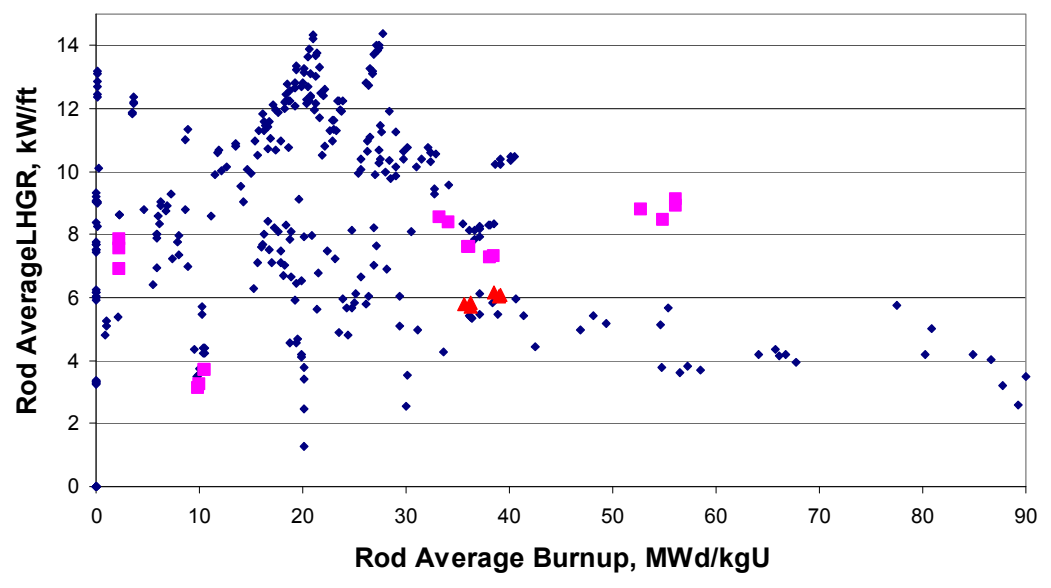

\begin{tabular}{|l|l|l|}
\hline IFA-558 \& $504 \mathrm{Kr}-85 \mathrm{~m}$ & $\Delta \mathrm{IFA}-633 \mathrm{Kr}-85 \mathrm{~m}$
\end{tabular}

Figure 1 Operating Range of $\mathrm{Kr}-85 \mathrm{~m}$ and I-131 Release Data, $R / B$, from IFA-558, IFA-504, and IFA-633 


\subsection{MODEL FITTING BASED ON HALDEN DATA}

The radioactive isotope that delivers the largest share to equivalent dose to individuals is generally I-131 (8.04-day half-life) for accidents during in-reactor operation or shortly after reactor operation (e.g., fuel handling accident) due to its dose to the thyroid and relatively long half-life. Therefore, the ANS 5.4 Working Group concentrated on developing the most accurate estimate of the I-131 release. However, as noted in Section 3.0, there were only 21 release measurements of I-131. The confidence in the coefficients model and the model predictive uncertainties developed from this small amount of data would be significant. As presented in Figure 1, there were hundreds of measurements over a wide range of operating conditions (burnup and rod power) for the $\mathrm{Kr}-85 \mathrm{~m}$ isotope. Because of the paucity of I-131 data and the large amount of noble gas data, it was decided to develop the diffusion coefficients of the release model and $S / V$ values both prior to and after interlinkage using the noble gas data. Because the diffusion coefficients for iodine and the noble gases are similar, ${ }^{9,11,12}$ the prediction of I-131 release should be relatively simple and can be verified by how well the model predicts the data of 21 measurements of I-131.

The $\mathrm{Kr}-85 \mathrm{~m}$ release data from the Halden experiments were selected for use to derive the coefficients to the ANS 5.4 model due to the relatively long half-life (4.48 hours). Other, longer-lived isotopes that are measured by Halden in the sweep gas are Xe-133 (5.25-day half-life) and Xe-135 (9.09-hour half-life); however, the release data for these isotopes have a larger uncertainty than for $\mathrm{Kr}-85 \mathrm{~m}$ measured release. For Xe-133, there are two reasons for the decrease in the measurement accuracy. The first is the lowenergy gamma of $\sim 80 \mathrm{keV}$ for Xe 133, while the other isotopes (including $\mathrm{Kr}-85 \mathrm{~m}$ ) have a much higher gamma energy with greater measurement accuracy. The detectors have been well calibrated at the higher energies but have not been well qualified at the lower energies near $80 \mathrm{keV}$ and do not have a uniform response (counting efficiency) across the energy spectrum. The second reason is that, at these low energies, there is a problem of high background that interferes with the Xe-133 measurement. For Xe-135, the production $B_{\mathrm{Xe}-135}$ of this isotope is not easily determined due to the fact that Xe-135 captures a neutron, creating stable Xe-136. The capture rate is both spectrum and flux dependent such that the quantity of Xe-135 can vary at different times in the reactor due to flux and spectrum changes. This makes the estimate of $B_{\mathrm{Xe}-135}$ difficult without detailed neutronic analyses throughout the irradiation.

The use of $\mathrm{Kr}-85 \mathrm{~m}$ for estimating the I-131 release is similar to the approach used by Turnbull ${ }^{8}$ in the mid 1980s. Turnbull estimated the I-131 release from Kr-85m release using his original diffusion coefficients (shown in Equations 5 through 8) derived from his measurement of noble gas release data from DIDO due to the lack of iodine release data at this time. Turnbull further assumed that the release of I-131 was essentially by single-atom diffusion and hence could be calculated by simply scaling by the square root of the ratio of the half-lives of a chosen gaseous fission product and I-131 using Equation 12 (no fractal effect). Since the longest-lived gas for which reliable data were generally found was Kr-85m with a 4.48hour half-life from his original experiments in DIDO, this isotope was chosen for the calculation. The $R / B$ for I-131 could therefore be written as:

$$
\left(\frac{R}{B}\right)_{131}=\left(\frac{R}{B}\right)_{85 m} \times \sqrt{\frac{\lambda_{85 m}}{\lambda_{131}}}
$$

This implies that $R / B$ for $\mathrm{I}-131$ is of the order of 6.56 times that for $\mathrm{Kr}-85 \mathrm{~m}$. In a later report, Turnbul1 ${ }^{24}$ used the 6.56 factor for comparison to the 21 measured release data of I-131 from IFA-504 and IFA-558. From these comparisons, he found that this methodology significantly over estimated the I-131 measurements made in the Halden sweep gas experiments described in Section 3.0. At this time, 
Turnbull hypothesized ${ }^{24}$ that this method contained a number of conservative assumptions that could explain the over prediction. His original hypothesis identified the following conservative assumptions:

1. The scaling process neglects the fact that $\mathrm{Kr}-85 \mathrm{~m}$ release is enhanced by rapid diffusion of its $\mathrm{Br}-85$ precursor. This is not the case for iodine isotopes.

2. The scaling process ignores the presence of a recoil release component.

3. Differentiating between diffusion coefficients, release of the shorter-lived $\mathrm{Kr}-85 \mathrm{~m}$ is best described using all three of the diffusion coefficient contributions, $D_{1}+D_{2}+D_{3}$ in Equation 5, while I-131 is best described using only $D_{1}+D_{2}$.

Based on further calculations, Turnbull concluded ${ }^{24}$ that the first two corrections were inadequate to reconcile the difference in prediction versus measured I-131 release, while the third was proved incorrect by finite difference calculations performed by White. ${ }^{22}$ White further concluded that it was not the diffusion coefficient that varied with the lifetime of the isotope, but the effective surface area based on the assumption that the uranium dioxide $\left(\mathrm{UO}_{2}\right)$ surface was actually a fractal effect. Applying the mathematics of fractals proposed by White leads to a constant scaling factor of 2.39 for I-131 release in relation to $\mathrm{Kr}-85 \mathrm{~m}$ release:

$$
\left(\frac{R}{B}\right)_{131}=2.39 \times\left(\frac{R}{B}\right)_{85 m}
$$

The fractal approach to diffusion is discussed in more detail in Section 2.0. Some members of the ANS 5.4 Working Group expressed doubt about the validity of the fractal phenomenon. The validity of the fractal phenomenon can be determined if Equation 13 for fractals can explain the relative release differences between long half-lived nuclides and short half-lived nuclides (e.g., a factor of 2.39 ratio between $R / B_{\mathrm{I}-131} / R / B_{\mathrm{Kr}-85 \mathrm{~m}}$ ). A disproof of a fractal effect would be if the release can be explained by a $\lambda^{0.5}$ (a factor of 6.59 ratio predicted for $R / B_{\mathrm{I}-131} / R / B_{\mathrm{Kr}-85 \mathrm{~m}}$ ) that assumes the diffusion distance for release is the same for both short- and long-lived nuclides.

There are some reliable release data from short-lived nuclides, but the release data of the long-lived nuclides are very limited or uncertain. For example, the only nuclide release data with long enough halflives to discern whether the fractal phenomenon is valid are the $R / B_{\mathrm{Xe}-133}$ and $R / B_{\mathrm{I}-131}$ data. One Working Group member felt that a small amount of release data from fuel irradiated at very low burnups ${ }^{25}$ did not show a fractal effect for measured values of $R / B_{\mathrm{Xe}-133}$, but there was also considerable scatter in these data. One of these measured $R / B_{\mathrm{Xe}-133}$ data (FIO-122) agrees with the 6.59 factor (no fractal effect), but the other data (FIO-124) suggest that the ratio factor between $R / B_{\mathrm{I}-131} / R / B_{\mathrm{Kr}-85 \mathrm{~m}}$ is less than the 2.39 fractal factor. Experimental measurements of $R / B_{\text {Xe-133 }}$ in Halden ${ }^{11}$ and by others ${ }^{26}$ have also shown very large uncertainty (scatter) in these data, making it difficult to discern whether the factor of 6.59 or 2.39 is valid for predicting the $R / B_{\mathrm{I}-131}$ release from $R / B_{\mathrm{Kr} 85 \mathrm{~m}}$ release, thus providing no conclusive evidence for either modeling approach. The Halden $R / B_{\mathrm{I}-131}$ data are currently the only data that exist over a wide range of burnups and rod powers for verification that the fractal factor of 2.39 is valid. The proposed uncertainty assumed for the new ANS 5.4 model is very conservative in relation to the $R / B_{\mathrm{I}-131}$ data such that it will bound any potential non-conservatism introduced by using the fractal mathematics, as will be demonstrated in the statistics of the model comparisons to the $R / B_{\mathrm{I}-131}$ data described in Section 4.4. 


\subsection{Development of Model Coefficients from $R / B_{\mathrm{Kr} 85 \mathrm{~m}}$ Data}

The coefficients in Equations 9 through 12 were derived using $174 R / B_{\mathrm{Kr} 85 \mathrm{~m}}$ release data from six rods irradiated in IFA-558 and $132 R / B_{\mathrm{Kr} 85 \mathrm{~m}}$ release data from four rods irradiated in IFA-504. Examination revealed that the release data from these two experimental assembly tests consisted of two separate populations. This is best illustrated by performing a best-estimate fit of the $R / B_{\mathrm{Kr} 85 \mathrm{~m}}$ data to determine the $S / V_{1}$ (before interlinkage) and $S / V_{2}$ (after interlinkage) values for each of these two instrumented fuel assemblies (IFAs) using the same three-term diffusion coefficient given above. The best-fit values of $S / V_{1}$ and $S / V_{2}$ from the IFA-504 $R / B_{\mathrm{Kr} 85 \mathrm{~m}}$ were $160 \mathrm{~cm}^{-1}$ and $800 \mathrm{~cm}^{-1}$, respectively; while the values for the IFA $R / B_{\mathrm{Kr} 85 \mathrm{~m}}$ were $80 \mathrm{~cm}^{-1}$ and $500 \mathrm{~cm}^{-1}$ as shown in Table 2.

Table 2 Values of $S / V_{1}$ and $S / V_{2}$ that Provide a Best-Estimate Fit of $R / B_{\mathrm{Kr} 85 \mathrm{~m}}$ Data Versus Burnup from Experimental Test Assemblies IFA-558 and IFA-504

\begin{tabular}{ccc}
\hline Experimental Test & $(S / V)_{1} \mathbf{c m}^{-1}$ & $(S / V)_{2} \mathbf{c m}^{-1}$ \\
\hline IFA-558 & 80 & 500 \\
IFA-504 & 160 & 800 \\
\hline
\end{tabular}

The difference in $S / V$ for these two data sets may be due to how the fuel was fabricated for these two experiments. The fuel from IFA-558 was more recently fabricated and considered to be more representative of today's fuel, while the IFA-504 fuel was from an older fabrication process that usually resulted in a higher open porosity than current fuel fabrication processes. Generally, a higher open porosity results in a higher $S / V$ and higher releases than fuel with a lower open porosity. However, there were no measurements of open porosity in either of these experiments; therefore, it is impossible to correlate the $S / V$ to open porosity in these experiments or to definitively conclude that one is nonprototypic of all fuel currently fabricated.

There have been other sweep gas experiments in Halden, but some are dated and less reliable than IFA-504 or the data are held proprietary. The Halden IFA-633 experiment collected sweep gas data from three $\mathrm{UO}_{2}$ and three mixed oxide (MOX) fuel rods from which there was a small amount of data (see Figure 1), but the currently available data only consist of six release data from the three $\mathrm{UO}_{2}$ rods. Use of only the IFA-558 data may not give a representative uncertainty in the release of current fuel types. Therefore, due to the lack of other radioactive noble or iodine release data, the IFA-504 data are included in the development of this model. As a result, $S / V$ best-estimate values from these two experiments were averaged providing values of $120 \mathrm{~cm}^{-1}$ and $650 \mathrm{~cm}^{-1}$ for $S / V_{1}$ and $S / V_{2}$, respectively, that resulted in a predicted-to-measured value near 1.0. This is reasonable since the number of release data from each experiment are similar (174 versus 132). The diffusion coefficients $\mathrm{D}_{1}, \mathrm{D}_{2}$, and $\mathrm{D}_{3}$ are those given in Equation 9, grain boundary interlinkage is given in Equations 10 and 11, and the fractal effect is given in Equation 13.

\subsection{Model Comparison to $R / B_{\mathrm{Kr} 85 \mathrm{~m}}$ Data}

Figures 2 and 3 show the ratio of predicted-to-measured values of $R / B_{\mathrm{Kr} 85 \mathrm{~m}}$ (assuming $S / V_{1}=120 \mathrm{~cm}^{-1}$ and $S / V_{2}=650 \mathrm{~cm}^{-1}$ for predictions) versus burnup under equilibrium conditions with the measured values from sweep gas experiments in Halden for test assemblies IFA-504 and IFA-558 as provided in References 9 and 22. A ratio greater than 1.0 indicates that the model is over predicting the data, while a value less than 1.0 indicates the model is under predicting the data. As expected, these figures show that the two experiments represent two different populations of release data and that deriving one set of $S / V$ values from these two populations results in under prediction of the IFA-504 data and over prediction of the IFA-558 data with the under and over predictions becoming greater at burnups above $13 \mathrm{MWd} / \mathrm{kgU}$. 
Figure 2 presents all of the data, while Figure 3 limits the burnup level to $40 \mathrm{MWd} / \mathrm{kgU}$ to better illustrate the differences between the two sets of experimental data.

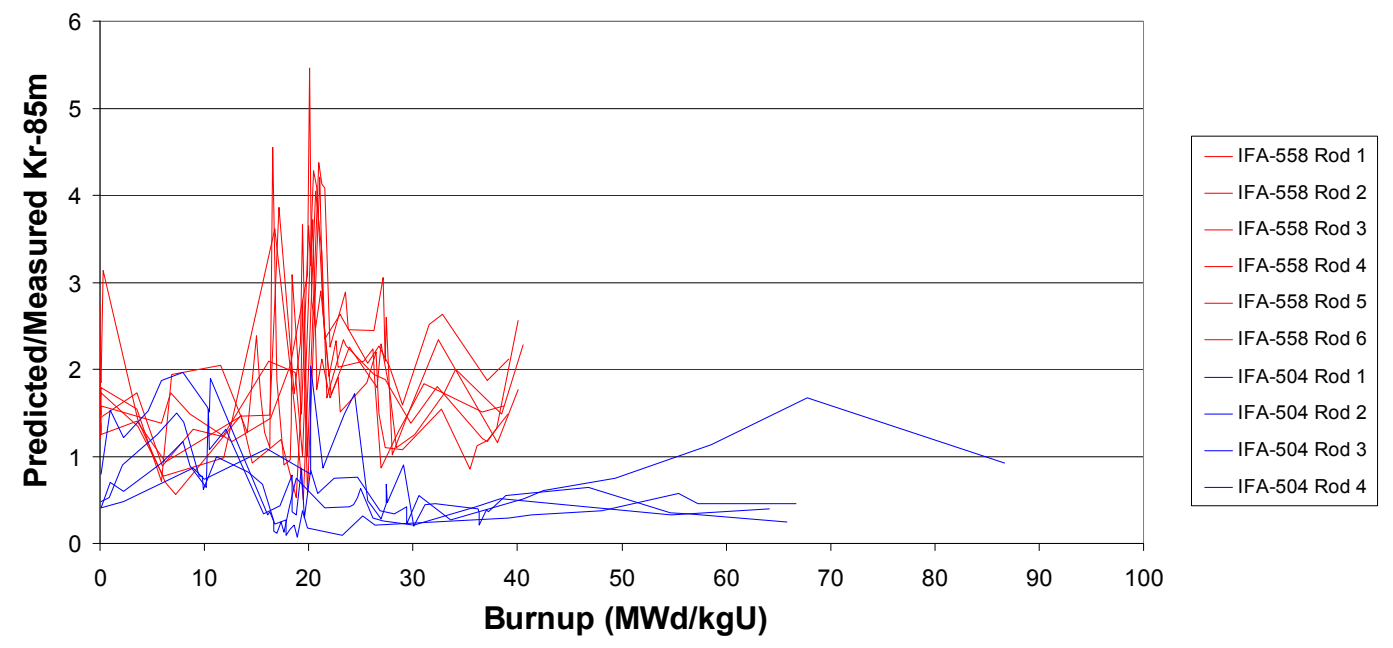

Figure 2 Ratio of Calculated $R / B_{\mathrm{Kr} 85 \mathrm{~m}}$ to Measured $R / B_{\mathrm{Kr} 85 \mathrm{~m}}$ Versus Burnup Between 0 and $90 \mathrm{MWd} / \mathrm{kgU}$ for Each of Six Experimental Rods in IFA-558 and Four Experimental Rods in IFA-504; Assumes $S / V_{1}=120 \mathrm{~cm}^{-1}$ and $S / V_{2}=650 \mathrm{~cm}^{-1}$

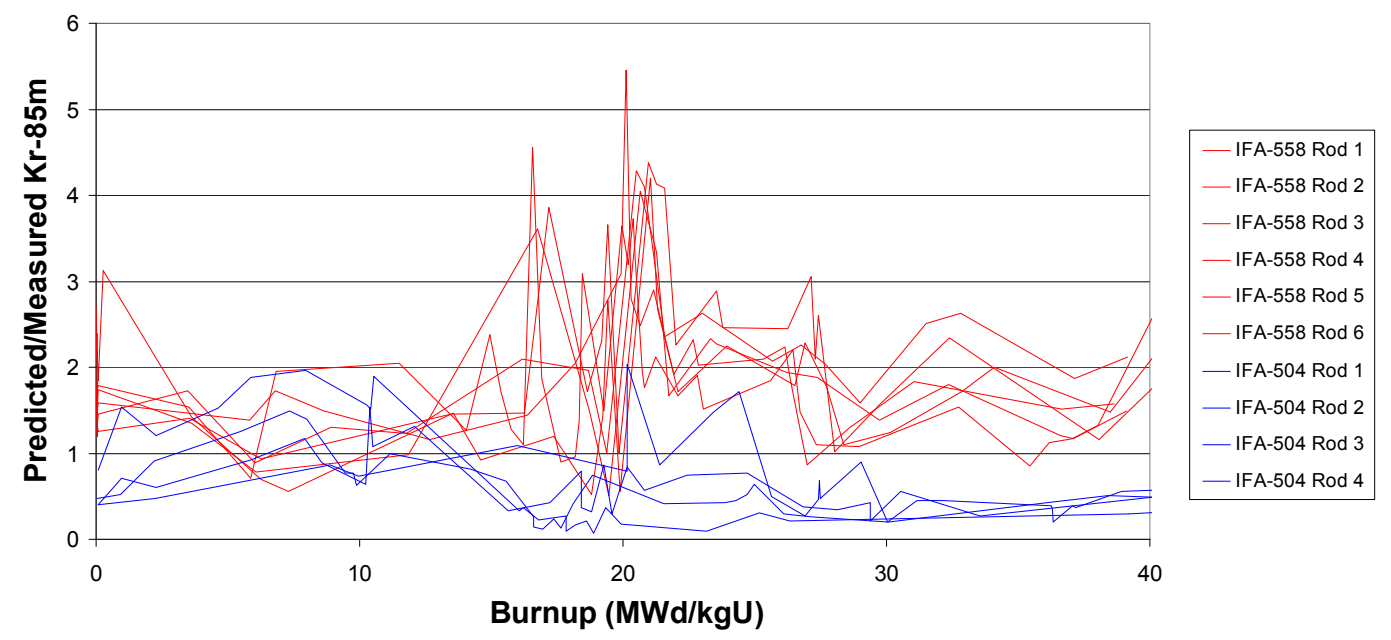

Figure 3 Ratio of Calculated $R / B_{\mathrm{Kr} 85 \mathrm{~m}}$ to Measured $R / B_{\mathrm{Kr} 85 \mathrm{~m}}$ Versus Burnup Between 0 and $40 \mathrm{MWd} / \mathrm{kgU}$ for Six Rods in IFA-558 (Red) and Four Rods in IFA-504 (Blue); Assumes $S / V_{1}=120 \mathrm{~cm}^{-1}$ and $S / V_{2}=650 \mathrm{~cm}^{-1}$

As noted above, the Halden reactor has recently published measurements of $R / B$ from three $\mathrm{UO}_{2}$ fuel rods (Rods 1, 3, and 5) at burnups between 35 and $40 \mathrm{MWd} / \mathrm{kgU}$ in the experimental assembly IFA-633. The Halden Reactor Project has indicated a plan to release additional data collected as part of the IFA-633 experiment, but these data are currently not available. These measurements are important to verify the validity of the proposed best-estimate release model and to determine if a correction is needed to the diffusion coefficients and $S / V$ for MOX fuel such that the standard can be modified to include MOX fuel. The ratio of model predicted to six measured values of $R / B_{\mathrm{Kr} 85 \mathrm{~m}}$ from the three $\mathrm{UO}_{2}$ IFA- 633 rods are presented in Figure 4 at burnups between 35 and $40 \mathrm{MWd} / \mathrm{kgU}$ along with the IFA-504 and IFA-558 data. 
Examination of this figure reveals that the four $R / B_{\mathrm{Kr} 85 \mathrm{~m}}$ measurements from Rods 3 and 5 are significantly over predicted by a factor of 5 to 7, while one of the Rod 1 predictions shows good agreement and the second Rod 1 prediction shows an under prediction of nearly a factor of two of the data (upper range of the IFA-504 ratios). These comparisons do not appear to resolve whether or not the IFA-504 data are representative of today's fuel because of one data point from Rod 1 of IFA-633 that was under predicted with a ratio of 0.59 . This under prediction is somewhat surprising considering the significant over prediction of the data from Rods 3 and 5 from IFA-633 and the fact that all of the $\mathrm{UO}_{2}$ fuel (Rods 1, 3, and 5) in this assembly were from the same fabrication source that is suppose to be representative of current $\mathrm{UO}_{2}$ fuel fabrication processes. This data comparison further demonstrates the need to include the IFA-504 data to provide an estimate in the uncertainty of the model for current fuel fabrication processes.

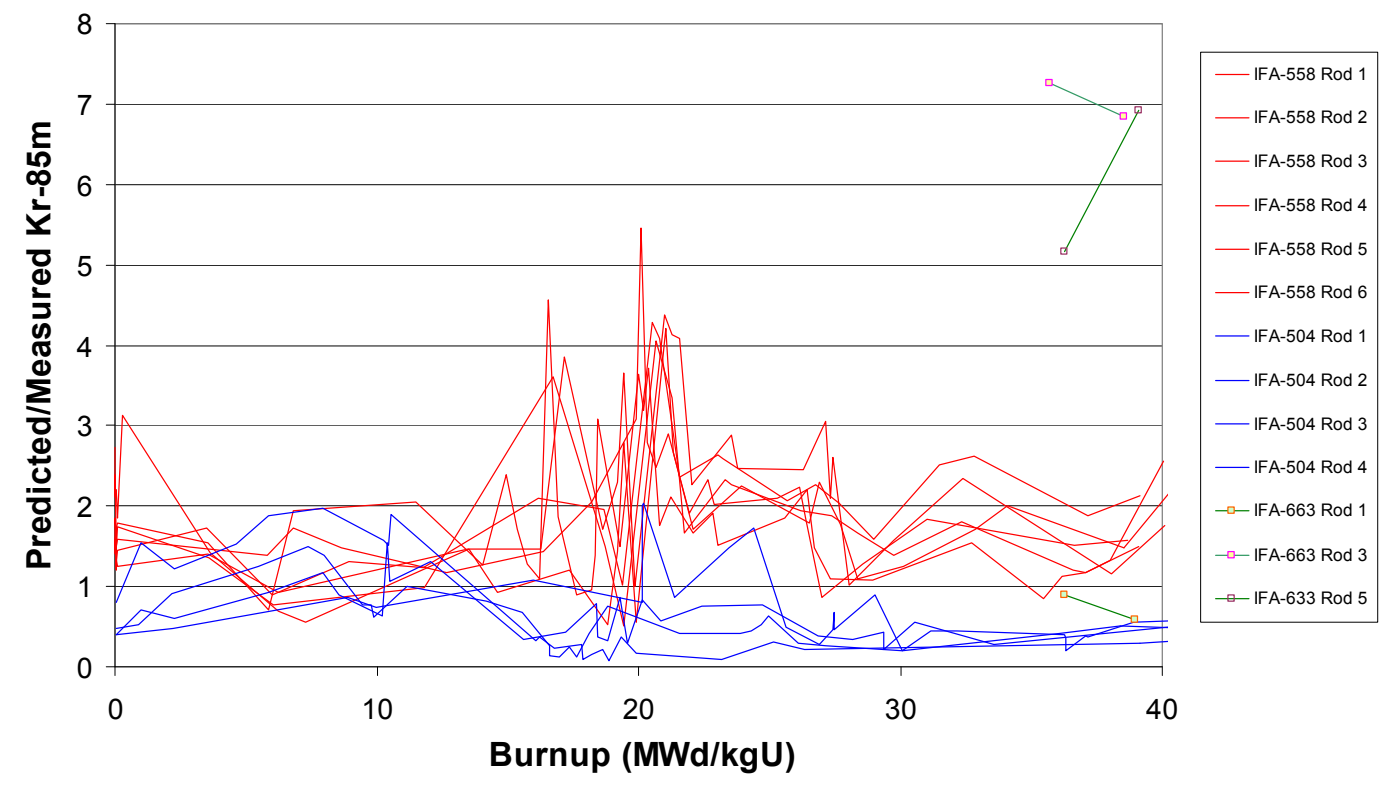

Figure 4 Ratio of Calculated $R / B_{\mathrm{Kr} 85 \mathrm{~m}}$ to Measured $R / B_{\mathrm{Kr} 85 \mathrm{~m}}$ versus Burnup for Six Rods in IFA-558 (Red), Four Rods in IFA-504 (Blue), and Three Rods in IFA-633 (Green); Assumes $S / V_{1}=120 \mathrm{~cm}^{-1}$ and $S / V_{2}=650 \mathrm{~cm}^{-1}$

The $R / B_{\mathrm{Kr} 85 \mathrm{~m}}$ predicted-to-measured ratios as a function of rod power are provided in Figure 5 to examine whether there are any biases in the model predictions with rod power. This figure appears to show that the model over prediction of the IFA-558 data increases with increasing rod powers above $10 \mathrm{~kW} / \mathrm{ft}$; however, the IFA-504 data does not show this trend. It should be noted that on average the IFA-558 data are over predicted by the model; but even within the IFA-558 data, the over prediction increases with rod power. This over prediction would suggest that the high-temperature diffusion term, $D_{1}$, should have smaller temperature dependence than assumed for the IFA-558 data. The $R / B_{\mathrm{I}-131}$ predictions will also be examined to determine if this trend exists with these data. 


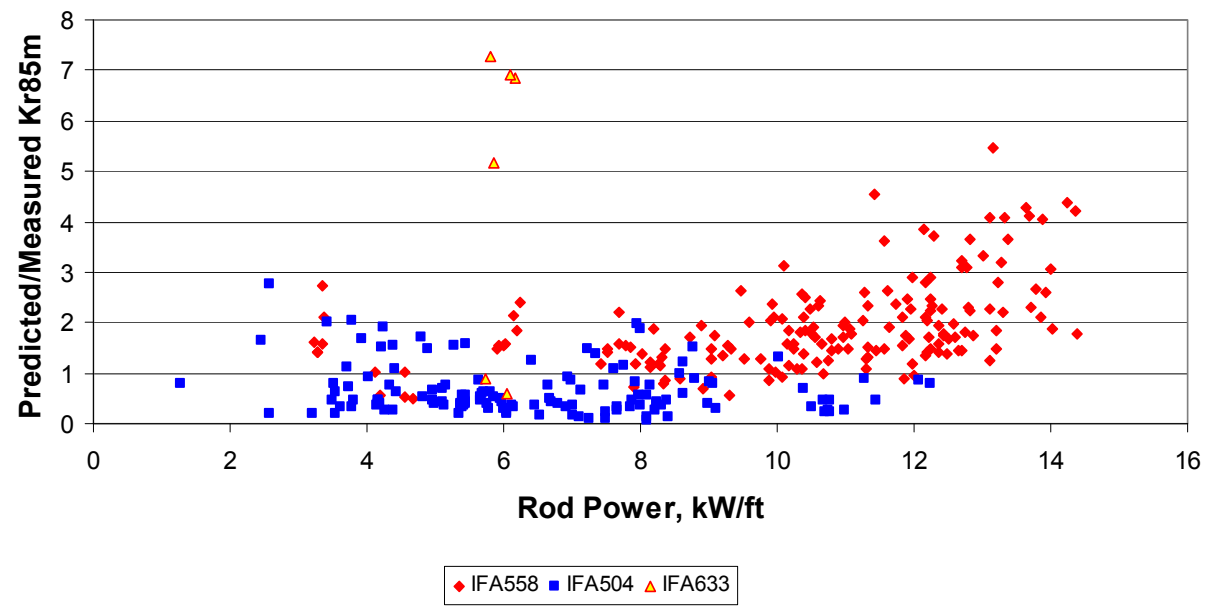

Figure 5 Ratio of Calculated $R / B_{\mathrm{Kr} 85 \mathrm{~m}}$ to Measured $R / B_{\mathrm{Kr} 85 \mathrm{~m}}$ Versus Rod Power for Six Rods in IFA558 (Diamond), Four Rods in IFA-504 (Square), and Three Rods IFA-633 (Triangle); Assumes $S / V_{1}=120 \mathrm{~cm}^{-1}$ and $S / V_{2}=650 \mathrm{~cm}^{-1}$

\subsection{Model Comparison to $R / B_{\mathrm{I}-131}$ Data}

The predicted-to-measured $R / B_{\mathrm{I}-131}$ is provided in Figure 6 and demonstrates that the model predictions are reasonably good. This suggests the data coefficients derived from $R / B_{\mathrm{Kr} 85 \mathrm{~m}}$ data apply to the release of I-131 and the assumptions used in the model development are valid. The ratio of predicted-to-measured values of $R / B_{\mathrm{I}-131}$ versus burnup (Figure 7) demonstrate that, on average, there is a small over prediction. The ratio of predicted-to-measured values of $R / B_{\mathrm{I}-131}$ versus rod power (see Figure 8 ) demonstrate that there is more scatter in the data at higher powers of 7 to $9 \mathrm{~kW} / \mathrm{ft}$, but there is no definitive bias with rod power. Overall, the model provides a reasonably accurate prediction of release for $R / B_{\mathrm{I}-131}$ considering uncertainties in the data and this is the form of model recommended for determining radiological release of the volatile nuclides.

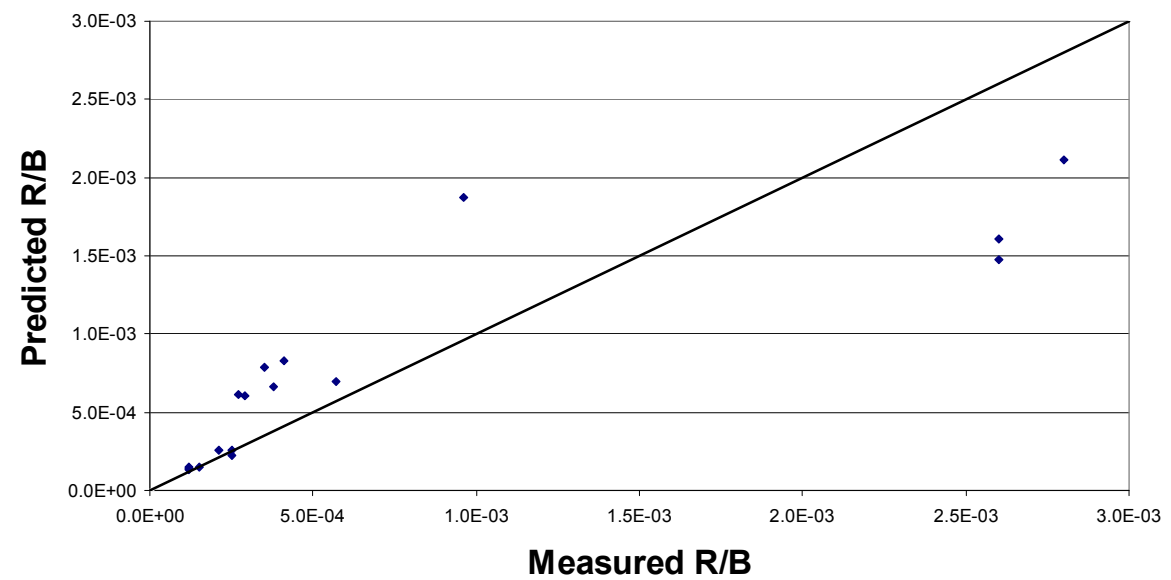

- $\mathrm{I}-131 \quad$ Predicted $=$ Measured - Linear $($ Predicted $=$ Measured $)$

Figure 6 Predicted to Measured $R / B$ for I-131 for IFA-558 and IFA-504; Assumes $S / V_{1}=120 \mathrm{~cm}^{-1}$ and $S / V_{2}=650 \mathrm{~cm}^{-1}$ 


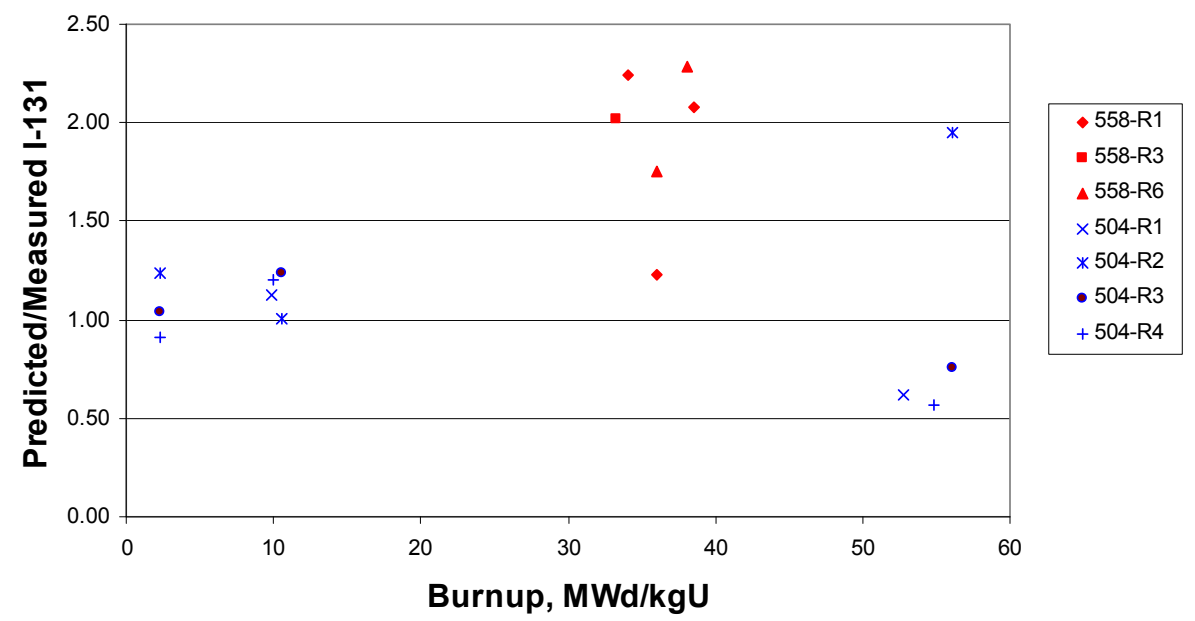

Figure 7 Ratio of Calculated $R / B_{\mathrm{I}-131}$ to Measured $R / B_{\mathrm{I}-131}$ Versus Burnup Between 0 and $56 \mathrm{MWd} / \mathrm{kgU}$ for Three Rods in IFA-558 (Red) and Four Rods in IFA-504 (Blue); Assumes $S / V_{1}=120 \mathrm{~cm}^{-1}$ and $S / V_{2}=650 \mathrm{~cm}^{-1}$

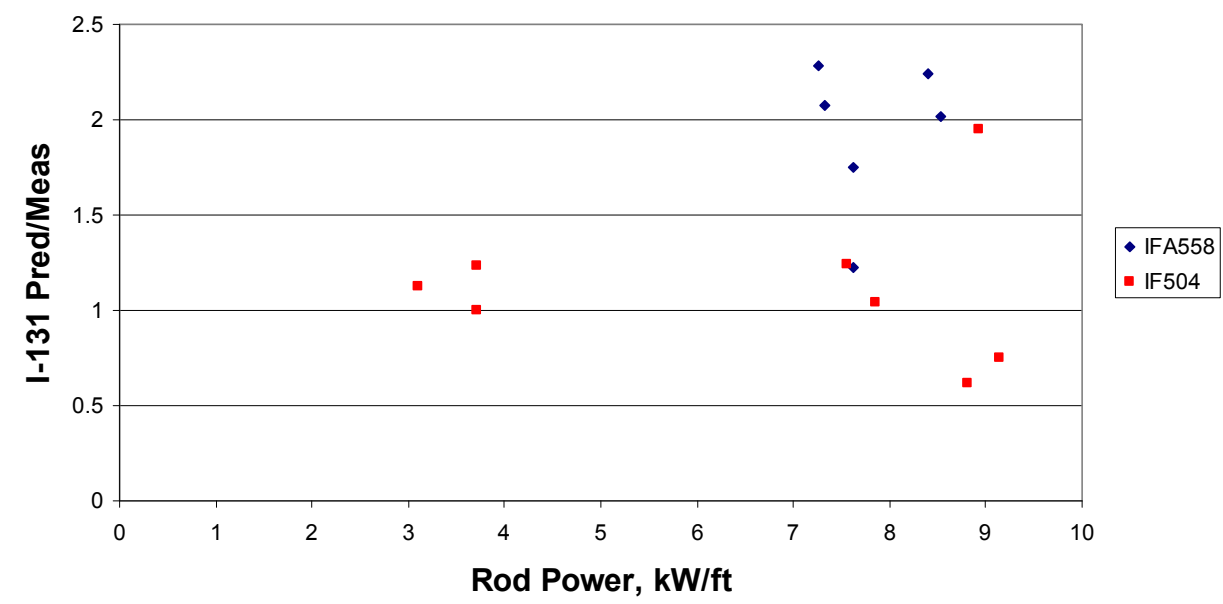

Figure 8 Ratio of Predicted $R / B_{\mathrm{I}-131}$ to Measured $R / B_{\mathrm{I}-131}$ Versus Rod Power for Three Rods in IFA-558 (Red) and Four Rods in IFA-504 (Blue); Assumes $S / V_{1}=120 \mathrm{~cm}^{-1}$ and $S / V_{2}=650 \mathrm{~cm}^{-1}$

\subsection{Estimate of Model Uncertainties}

The uncertainty in model predictions will be assessed in terms of the predictions of the Kr-85m and I-131 data separately because there is a significant difference in uncertainty in the model prediction of these two data sets.

\subsubsection{Estimate of Model Uncertainties from Predictions of $R / B_{\mathrm{Kr}-85 \mathrm{~m}}$ Data}

The $R / B_{\text {Kr85m }}$ release values (see Figure 9) vary by over two orders of magnitude; therefore, in order to normalize these large differences, the statistical analysis was performed on the Ln P/M. The IFA-504 and IFA-558 ratio of predicted to measured represent two separate distributions (particularly at burnups greater than $10 \mathrm{MWd} / \mathrm{kgU}$ ), both of which are nearly normal as illustrated in Figures 3 and 4; therefore, this combined data set represents a bi-normal distribution. Assuming a normal distribution for the 
combined data set is a non-conservative assumption, but assuming they are a non-normal data set is a conservative assumption. Therefore, a non-normal distribution was chosen to determine the upper 95/95 bounding model uncertainty for predicting the $R / B_{\mathrm{Kr} 85 \mathrm{~m}}$. A mean and a standard deviation for a nonnormal distribution do not have any statistical meaning such that the multiplier, $\mathrm{K}_{95 / 95}$, on a prediction is based on an nth largest negative value of under prediction from the database where the nth value is determined from the number of data used to establish model coefficients. Utilizing the non-normal distribution at a $95 / 95$ tolerance level (bounding with $95 \%$ probability at a $95 \%$ confidence level) for 300 data points (given in Table 2 of Regulatory Guide $1.126^{27}$ ), the ninth largest negative value of $\mathrm{Ln} \mathrm{P} / \mathrm{M}$ (under prediction) is -1.616 , which represents an under prediction of 5.03 from the measured value. In order to bound future predictions at a 95/95 tolerance level, the best-estimate model prediction is multiplied by 5.03 , which is rounded to 5 considering the data and conservatisms in this estimate. Figure 9 provides the $95 / 95$ tolerance upper-bound predictions compared to the $R / B_{\mathrm{Kr} 85 \mathrm{~m}}$ data.

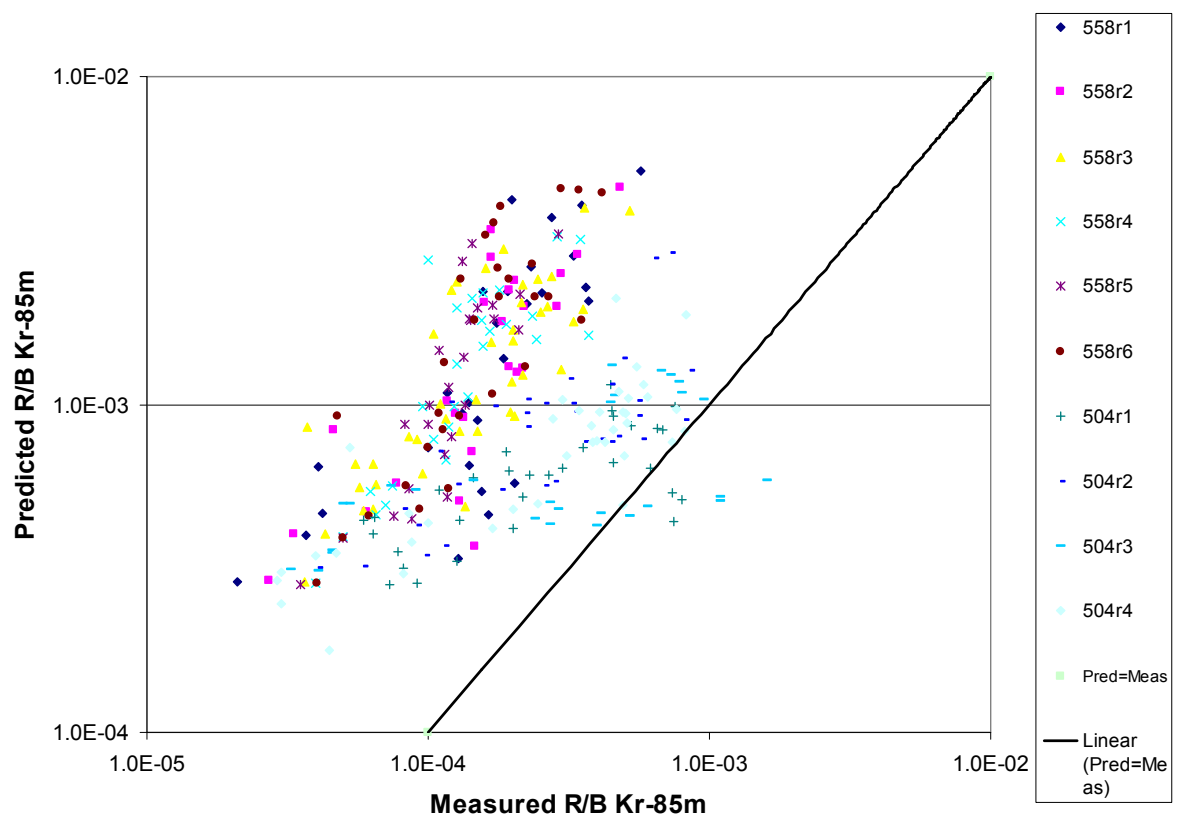

Figure 9 Predicted 95/95 (Assuming Non-Normal) $R / B_{\mathrm{Kr}-85 \mathrm{~m}}$ Versus Measured $R / B_{\mathrm{Kr}-85 \mathrm{~m}}$ from IFA-504 and IFA-558

\subsubsection{Estimate of Model Uncertainties from Predictions of $R / B_{\mathrm{I}-131}$ Data}

A similar statistical analysis was performed for the model predictions of the $R / B_{\mathrm{I}-131}$ data with the exception that a normal distribution was assumed based on examination of Figures 6 and 7. The mean of the $\mathrm{Ln} \mathrm{P} / \mathrm{M}$ is 0.2263 (over prediction) with a standard deviation of 0.4381 . There were $17 R / B_{\mathrm{I}-131}$ data with three degrees of freedom; therefore, the $\mathrm{K}_{95 / 95}$ tolerance factor becomes $\exp (-0.2263+2.5888 * 0.4381)$ $=2.48$. This value is a factor of 2 lower than the $\mathrm{K}_{95 / 95}$ tolerance factor, 5 , derived from the $R / B_{\mathrm{Kr} 85 \mathrm{~m}}$ data. It is recommended that the factor of 5 from the $R / B_{\mathrm{Kr} 85 \mathrm{~m}}$ data comparisons also be used for predictions of all radioactive isotopes, including I-131 predictions that will address the concerns about the validity of the fractal factor used to perform the best-estimate predictions of the $R / B_{\mathrm{I}-131}$ data. Using a $\mathrm{K}_{95 / 95}$ tolerance factor of 5 for predicting the $R / B_{\mathrm{I}-131}$ data demonstrates a very conservative over prediction of these data (see Figure 10). 


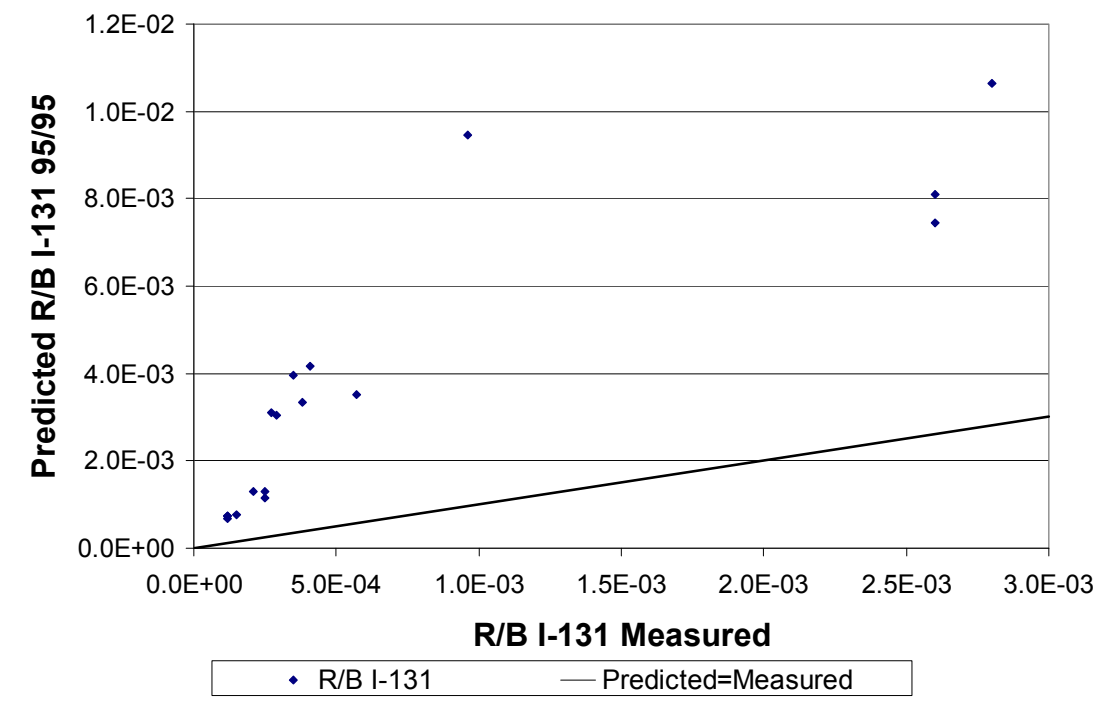

Figure 10 Predicted 95/95 (Assuming Non-Normal) $R / B_{\mathrm{I}-131}$ Versus Measured $R / B_{\mathrm{I}-131}$ from IFA-504 and IFA-558

Upper-bound 95/95 tolerance predictions (using a factor of 5) of $R / B_{\mathrm{I}-131}$ of the new proposed ANS 5.4 model have been performed with the FRAPCON $-3.3^{28}$ fuel rod performance code used to provide fuel temperature predictions for a generic boiling water reactor (BWR) 10x10 fuel design; the results are provided in Figure 11. The power history used assumed a rod average power of $31.5 \mathrm{~kW} / \mathrm{m}$ up to a burnup of $22 \mathrm{MWd} / \mathrm{kgU}$, then decreased linearly to $23.5 \mathrm{~kW} / \mathrm{m}$ at $62 \mathrm{MWd} / \mathrm{kgU}$ (rod average). Also included in Figure 11 is a calculation using the same code and BWR 10x10 input, but using the old ANS 5.4 model for calculating the $R / B_{\mathrm{I}-131}$. This illustrates how the new proposed ANS 5.4 model provides a factor of 2 less peak release for iodine isotopes than the old model for fuel rod average burnups greater than $30 \mathrm{MWd} / \mathrm{kgU}$.

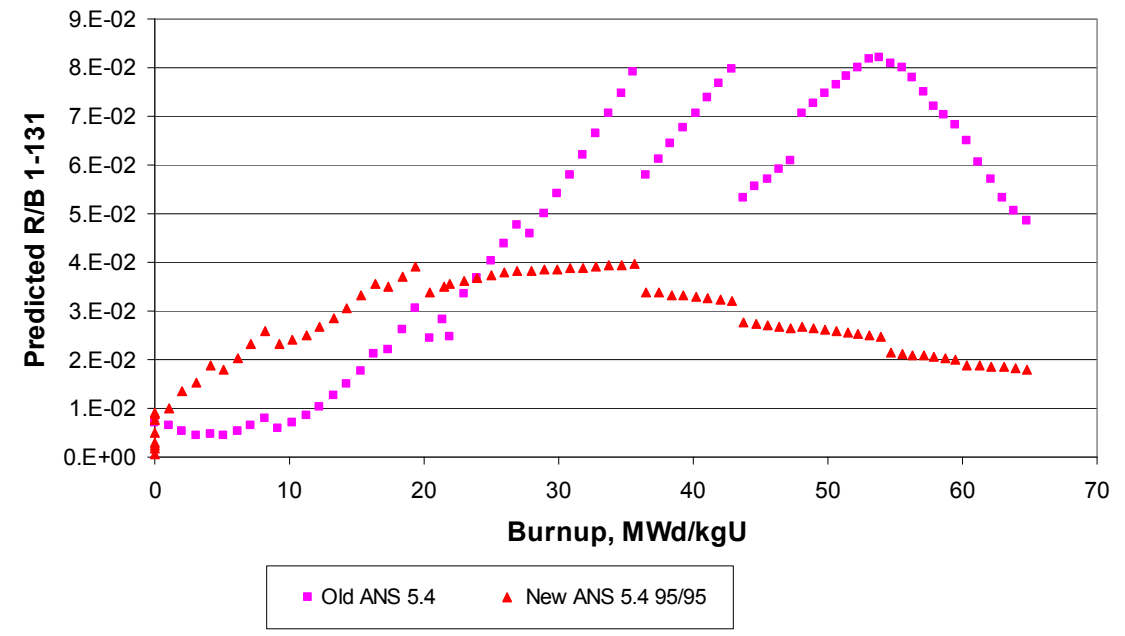

Figure 11 Comparison of New ANS 5.4 Model Upper Bound at 95/95 $R / B_{\mathrm{I}-131}$ Predictions to Old ANS 5.4 Model $R / B_{\mathrm{I}-131}$ Predictions for a BWR 10x10 Fuel Design 


\subsection{Assumptions and Limitations}

The assumptions used in model development are:

1. Gas-atom diffusion from where the atoms are born in the fuel matrix is the mechanism for diffusion to the grain boundaries where the gas precipitates as bubbles.

2. The gas bubbles on the grain boundaries reach a saturation point where the bubbles interlink, releasing the gas to the fuel rod void volume.

3. The criterion for grain boundary interlinkage is a function of only temperature and burnup.

4. Once the grain boundary interlinkage has occurred, the grain boundary remains linked to the rod internal void volume for the rest of the irradiation (i.e., no resintering of the grain boundary is experienced).

5. The nuclides are in radioactive equilibrium in terms of release and decay, which is approximately correct if fuel temperatures remain constant for at least three half-lives of the nuclide.

6. Precursor effects can be accounted for by a multiplier, $\alpha$, on the diffusion coefficient, per Friskney and Speight. ${ }^{8}$ The diffusion coefficients for the bromine and tellurium precursors are assumed to be a factor of 4 and 20 greater, respectively, than the noble gases and iodines.

The limitations of the developed model are the following:

- The model does not account for burst releases due to large sudden temperature (power) increases greater than $300^{\circ} \mathrm{K}$.

- The model does not account for transport of fission products after release from the fuel rod due to a cladding defect.

- The model does not apply to release of stable nuclides or nuclides with half-lives greater than one year. Other models are available to determine release of stable nuclides.

- Application of the model to predict release with temperature changes on the order of less than three half-lives for an isotope can be performed in a conservative manner by assuming the maximum temperature during the time period has been constant for the three half-lives of the isotope.

- The model does not apply to release from failed fuel where fuel oxidation is possible. Fuel oxidation can enhance the radiological release.

- The model does not apply to commercial fuel operation with rod-average burnups greater than $70 \mathrm{MWd} / \mathrm{kgU}$. Data used for model development extend to $90 \mathrm{MWd} / \mathrm{kgU}$ but are at relatively low linear heat generation rates between 70 to $90 \mathrm{MWd} / \mathrm{kgU}$.

- The model is based on fuel with densities between $95 \%$ to $98 \%$ of theoretical density, grain sizes between 6 to $15 \mu \mathrm{m}$ (mean linear intercept), and open porosities between $0.1 \%$ to $3.0 \%$ theoretical density. Therefore, the model should only be applied to fuel within these ranges.

- The model is based on release from $\mathrm{UO}_{2}$ fuel only; therefore, it currently does not apply to $(\mathrm{U}, \mathrm{Pu}) \mathrm{O}_{2}$ fuel or fuel types other than $\mathrm{UO}_{2}$. The ANS 5.4 Working Group and the NRC are in discussions with the Halden Reactor Project to release those data applicable to $(\mathrm{U}, \mathrm{Pu}) \mathrm{O}_{2}$ fuel to the NRC (a member of the project). Once these data are received, an assessment can be performed to determine whether the current model can be applied to predicting gap release fractions for $(\mathrm{U}, \mathrm{Pu}) \mathrm{O}_{2}$ fuel. 


\subsection{CONCLUSIONS}

A newly proposed ANS 5.4 release model has been developed for determining the radioactive fission product releases for use in assessing radiological consequences of postulated accidents that do not involve abrupt power transients. This proposed ANS 5.4 model has been reviewed by the ANS 5.4 Working Group, and submitted for approval as the new ANS 5.4 standard. When used with isotopic yields, this proposed model will predict the "gap activity," which is the inventory of volatile fission products that are released from the fuel rod if the cladding is breached. The standard model as developed applies to steadystate conditions and, therefore, should not be applied to accidents where abrupt temperature increases are experienced, resulting in a "burst release." The standard does not consider escape-rate coefficients or other descriptions of the transport of fission products after release from the fuel rod void space. The standard assumes that no significant fuel oxidation will be present during the accident because fuel oxidation can significantly enhance the release.

This report describes both best-estimate and conservative upper-bound 95/95 tolerance models for predicting the release of volatile radioactive isotopes of krypton, xenon, and iodine. The conservative upper-bound model for predicting the I-131 release is very conservative in comparison to the available measured release data for I-131. The new proposed model predicts up to a factor of 2 lower release than the old ANS 5.4 release model. 



\subsection{REFERENCES}

1. American Nuclear Society, Method for Calculating the Fractional Release of Volatile Fission Products from Oxide Fuel, ANSI/ANS 5.4 -1982 Also defined in S.E. Turner et al., "Background and Derivation of ANS-5.4 Standard Fission Product Release Model," U.S. Nuclear Regulatory Commission Report, NUREG/CR-2507, 1982.

2. A.H. Booth, "A Method for Calculating Fission Gas Diffusion from $\mathrm{UO}_{2}$ Fuel and its Application to the X-2-f Loop Test," Atomic Energy of Canada Report, CRDC-721, 1957.

3. A.H. Booth, "A Suggested Method for Calculating the Diffusion of Radioactive Rare Gas Fission Products from $\mathrm{UO}_{2}$ Fuel Elements and a Discussion of Proposed In-Reactor Experiments that May Be Used to Test its Validity,” DCI-27 AECL-700, Atomic Energy of Canada Limited, 1957.

4. A.H. Booth and G.T. Rymer, "Determination of the Diffusion Constant of Fission Xenon in $\mathrm{UO}_{2}$ Crystals and Sintered Compacts," Atomic Energy of Canada Report, CRDC-720, 1958.

5. W.N. Rausch and F.E. Panisko, "ANS54: A Computer Subroutine for Predicting Fission Gas Release,” U.S. Nuclear Regulatory Commission Report, NUREG/CR-1213, 1979.

6. J.A. Turnbull and C.A. Friskney, "The Relation Between Microstructure and the Release of Unstable Fission Products During High-Temperature Irradiation of Uranium Dioxide," Journal of Nuclear Materials, vol. 71, issue 2, January 1978.

7. C.A. Friskney and M.V. Speight, "A Calculation on the In-Pile Diffusional Release of Fission Products Forming a General Decay Chain," Journal of Nuclear Materials, vol. 62, October 1976.

8. J.A. Turnbull, “A Model for Calculating the Gap Inventory of ${ }^{131} \mathrm{I}$ in Intact Fuel Rods," Paper 56, BNES Conference on Nuclear Fuel Performance, London 1985.

9. J.A. Turnbull, R.J. White, and C. Wise, "The Diffusion Coefficient for Fission Gas Atoms in Uranium Dioxide," IAEA Conference, Preston, Lancs, UK, IAEA-TC-659/3.5, 1988.

10. J.A. Turnbull et al., "The Diffusion Coefficients of Gaseous and Volatile Species During the Irradiation of Uranium Dioxide," Journal of Nuclear Materials, vol. 107, issues 2-3, June 1982.

11. R.J. White and J.A. Turnbull, "The Measurement of Fission Product Release Using the Gas Flow Rigs: A Review of Experiments, Methodology and Results from 1980-1997," OECD Halden Project Report No. HWR-553, February 1998.

12. B.J. Lewis, C.E.L. Hunt, and F.C. Iglesias, "Source Term of Iodine and Noble Gas Fission Products in the Fuel-to-Sheath Gap of Intact Operating Nuclear Fuel Elements," Journal of Nuclear Materials, vol. 172, pp. 197-205, 1990.

13. J. Killeen, E. Skattum, and A. Haaland, "Review of Thermal Behaviour and Fission Product Release From the Gas Flow Rig IFA-504,” OECD Halden Reactor Project Report, HWR-187, April 1987.

14. B.J. Lewis, B. Andre, G. Ducros, and D. Maro, "A Model for Nonvolatile Fission Product Release During Reactor Accident Conditions," Nuclear Technology, vol. 116, pp. 34-54, October 1996.

15. S.G. Prussin, D.R. Olander, W.K. Lau, and L. Hansson, "Release of Fission Products (Xe, I, Te, Cs, Mo and Tc) From Polycrstalline $\mathrm{UO}_{2}$," Journal of Nuclear Materials, vol. 154, pp. 25-37, 1988.

16. J.P. Leveque et al., "The HEVA Experimental Program,” Nuclear Technology, vol. 108, p. 33, 1994.

17. D. Davies and G. Long, AERE Report No. 4347, 1963. 
18. H.J. Matzke, "Gas Release Mechanisms in $\mathrm{UO}_{2}$ - A Critical Review," Proc. Int. Summer School on the Physics of Ionized Gases, Hercegnovi, Yugoslavia, 1970. Also Irradiation Effects, vol. 53, pp. 219-242, 1980.

19. M.O. Tucker and J.A. Turnbull, International Conference on Physical Metallurgy of Reactor Fuel Elements, Berkeley Nuclear Laboratories, Gloucestershire, UK, September 2-7, 1973.

20. D.M. Dowling, R.J. White, and M.O. Tucker, "The Effect of Irradiation-Induced Re-Solution on Fission Gas Release," Journal of Nuclear Materials, vol. 110, issue 1, August 1983.

21. C. Vitanza , E. Kolstad, and V. Graziani, "Fission Gas Release from $\mathrm{UO}_{2}$ Pellet Fuel at High Burnup," ANS Topical Meeting on LWR Fuel Performance. Portland, Oregon, May 1979.

22. R.J. White, "The Fractal Nature of the Surface of Uranium Dioxide: A Resolution of the ShortLived/Stable Gas Release Dichotomy," OECD Halden Reactor Report No. HWR-550, February 1998. Also published in Journal of Nuclear Materials, vol. 295, issues 2 and 3, pp. 133-148, June 2001.

23. E. Rø and G.D. Rossiter, "The SBR MOX and UO2 Comparison Test in Gas Flow Rig IFA-633: An Update of Results," HWR-823, Enlarged Halden Programme Group Meeting, Lillehammer, Norway, October 2005.

24. J.A. Turnbull, "The Treatment of Radioactive Fission Product Release Measurements and Provision of Data for Development and Validation of the ANS Model," OECD Halden Reactor Project Report No. HWR-667, February 2001.

25. T.J. Hastings et al. "Tests to Determine the Release of Short-Lived Fission Products from $\mathrm{UO}_{2}$ Fuel Operating at Linear Powers of 45 and 60 kW/m: Methods and Results," AECL-7920, Atomic Energy of Canada Limited, Chalk River Laboratories, Chalk River, Ontario, Canada, September 1985.

26. M. Charles, P. Chenebault, and P. Melin, "Mechanisms of Fission Gas Release from Different Types of Fuel Rods During Normal Operation: Results and Analysis of "CONTACT" Experiments," Light Water Reactor Fuel Performance Proceedings, Orlando, Florida, April 21 -24, 1985, DOE/NE/34130-1, vol. 2, pp. 4-53.

27. U.S. Nuclear Regulatory Commission, Regulatory Guide 1.126, An Acceptable Model and Related Statistical Methods for the Analysis of Fuel Densification, March 1977.

28. Lanning, D.D., C.E. Beyer, and K.J. Geelhood. 2005, FRAPCON-3 Updates, including Mixed Oxide Properties, NUREG/CR-6534 (PNNL-11513) Vol. 4, U.S. Nuclear Regulatory Commission, Washington D.C. 


$\begin{aligned} & \text { NRC FORM } 335 \\ & \text { (9-2004) } \\ & \text { NRCMD } 3.7\end{aligned}$

BIBLIOGRAPHIC DATA SHEET

(See instructions on the reverse)
1. REPORT NUMBER

(Assigned by NRC, Add Vol., Supp., Rev., and Addendum Numbers, if any.)

NUREG/CR-7003

2. TITLE AND SUBTITLE

Background and Derivation of ANS-5.4 Standard Fission Product Release Model

MONTH $\quad$ YEAR

JANUARY $\quad 2010$

4. FIN OR GRANT NUMBER

NRC Job Code N6326

5. AUTHOR(S)

J.A. Turnbull and C.E. Beyer

6. TYPE OF REPORT

Technical

7. PERIOD COVERED (Inclusive Dates)

8. PERFORMING ORGANIZATION - NAME AND ADDRESS (If NRC, provide Division, Office or Region, U.S. Nuclear Regulatory Commission, and mailing address; if contractor, provide name and mailing address.)

Pacific Northwest National Laboratory

902 Battelle Blvd. P.O. Box 999

Richland, WA 99352

9. SPONSORING ORGANIZATION - NAME AND ADDRESS (If NRC, type "Same as above"; if contractor, provide NRC Division, Office or Region, U.S. Nuclear Regulatory Commission, and mailing address.)

Division of Systems Analysis

Office of Nuclear Regulatory Research

U.S. Nuclear Regulatory Commission

Washington DC 20555-0001

10. SUPPLEMENTARY NOTES

11. ABSTRACT (200 words or less)

This background report describes the technical basis for the newly proposed American Nuclear Society (ANS) 5.4 standard, Methods for Calculating the Fractional Release of Volatile Fission Products from Oxide Fuels. The proposed ANS 5.4 standard provides a methodology for determining the radioactive fission product releases from the fuel for use in assessing radiological consequences of postulated accidents that do not involve abrupt power transients. When coupled with isotopic yields, this method establishes the "gap activity," which is the inventory of volatile fission products that are released from the fuel rod if the cladding is breached.

Best-estimate and conservative upper-bound 95/95 tolerance models for predicting the release of volatile radioactive isotopes of krypton, xenon, and iodine are described. The isotope that provides the most significant contribution to equivalent dose to individuals is generally $\mathrm{l}-131$ for accidents that occur during in-reactor operation or shortly after reactor operation (e.g., the fuel-handling accident) due to its dose to the thyroid. The existing conservative upper-bound model for predicting the l-131 release has been shown to be very conservative in comparison to the available measured release data for I-131. The proposed 2009 model predicts up to a factor of 2 lower release than the old ANS 5.4 release model.

12. KEY WORDS/DESCRIPTORS (List words or phrases that will assist researchers in locating the report.)

\begin{tabular}{|c|}
\hline $\begin{array}{l}\text { 13. AVAILABILITY STATEMENT } \\
\text { unlimited }\end{array}$ \\
\hline 14. SECURITY CLASSIFICATION \\
\hline (This Page) \\
\hline unclassified \\
\hline (This Report) \\
\hline unclassified \\
\hline 15. NUMBER OF PAGES \\
\hline 16. PRICE \\
\hline
\end{tabular}

Fission products

Radionuclide and fission gas release

Nuclear fuel performance code 


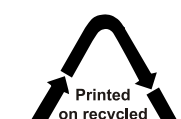

Printed
on recycled
paper

paper

Federal Recycling Program 



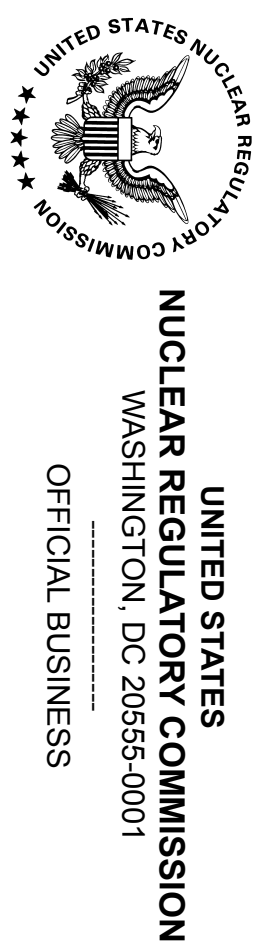

